Corresponding author: jenny.taylor@well.ox.ac.uk

(C) 2018 Schuh et al. This article is distributed under the terms of the Creative Commons Attribution-NonCommercial License, which permits reuse and redistribution, except for commercial purposes, provided that the original author and source are credited.

Ontology terms: colon cancer; cutaneous leiomyosarcoma; endometrial carcinoma; neoplasm of the breast; pharyngeal neoplasm; prostate cancer

Published by Cold Spring Harbor Laboratory Press

doi: $10.1101 /$ mcs.a002279

\section{Clinically actionable mutation profiles in patients with cancer identified by whole-genome sequencing}

\author{
Anna Schuh, ${ }^{1,2}$ Helene Dreau, ${ }^{1,3}$ Samantha J.L. Knight, ${ }^{2,4}$ Kate Ridout, ${ }^{2,3}$
} Tuba Mizani, ${ }^{1,2}$ Dimitris Vavoulis, ${ }^{2,3}$ Richard Colling, ${ }^{1,3}$ Pavlos Antoniou, ${ }^{5}$ Erika M. Kvikstad, ${ }^{2,4}$ Melissa M. Pentony, ${ }^{2,4}$ Angela Hamblin, ${ }^{6}$ Andrew Protheroe, ${ }^{7}$ Marina Parton, ${ }^{8}$ Ketan A. Shah, ${ }^{9}$ Zsolt Orosz, ${ }^{8,9}$ Nick Athanasou, ${ }^{10}$ Bass Hassan, ${ }^{11}$ Adrienne M. Flanagan, ${ }^{12}$ Ahmed Ahmed, ${ }^{13}$ Stuart Winter, ${ }^{14}$ Adrian Harris, ${ }^{15}$ Ian Tomlinson, ${ }^{4}$ Niko Popitsch, ${ }^{16}$ David Church, ${ }^{4}$ and Jenny C. Taylor ${ }^{2,4}$

\begin{abstract}
${ }^{1}$ Oxford Molecular Diagnostics Centre, Department of Oncology, University of Oxford, Oxford OX3 9DU, United Kingdom; ${ }^{2}$ Oxford NIHR Biomedical Research Centre, Oxford OX4 2PG, United Kingdom; ${ }^{3}$ Nuffield Department of Clinical Laboratory Sciences, University of Oxford, Oxford OX3 9DU, United Kingdom;

${ }^{4}$ Wellcome Centre for Human Genetics, University of Oxford, Oxford OX3 7BN, United Kingdom; ${ }^{5}$ Cambridge University Hospitals NHS Foundation Trust, Cambridge Biomedical Campus, Cambridge CB2 0QQ, United Kingdom; ${ }^{6}$ Department of Haematology, Oxford University Hospitals NHS Foundation Trust, Oxford OX3 9DU, United Kingdom; ${ }^{7}$ Oxford Cancer and Haematology Centre, Oxford University Hospitals NHS Foundation Trust, Oxford OX3 7LE, United Kingdom; ${ }^{8}$ Breast Unit, Royal Marsden NHS Foundation Trust and Kingston NHS Foundation Trust, London SW3 6JJ, United Kingdom; ${ }^{9}$ Department of Cellular Pathology, Oxford University Hospitals NHS Foundation Trust, Oxford OX3 9DU, United Kingdom; ${ }^{10}$ Nuffield Department of Orthopaedics, Rheumatology and Musculoskeletal Sciences, University of Oxford, Oxford OX3 7LD, United Kingdom; ${ }^{11}$ Sir William Dunn School of Pathology, University of Oxford, Oxford OX1 3RE, United Kingdom; ${ }^{12}$ University College London, Cancer Institute and Royal National Orthopaedic NHS Hospital, London WC1E 6BT, United Kingdom; ${ }^{13}$ Nuffield Department of Obstetrics and Gynaecology, University of Oxford, Oxford OX3 9DU, United Kingdom; ${ }^{14}$ Department of Ear Nose and Throat-Head and Neck Surgery, Oxford University Hospitals, Oxford OX3 9DU, United Kingdom; ${ }^{15}$ Department of Oncology, University of Oxford, Oxford OX3 7DQ, United Kingdom; ${ }^{16}$ The Children's Cancer Research Institute (CCRI), 1090 Vienna, Austria
\end{abstract}

Abstract Next-generation sequencing (NGS) efforts have established catalogs of mutations relevant to cancer development. However, the clinical utility of this information remains largely unexplored. Here, we present the results of the first eight patients recruited into a clinical whole-genome sequencing (WGS) program in the United Kingdom. We performed PCR-free WGS of fresh frozen tumors and germline DNA at $75 \times$ and $30 \times$, respectively, using the HiSeq2500 HTv4. Subtracted tumor VCFs and paired germlines were subjected to comprehensive analysis of coding and noncoding regions, integration of germline with somatically acquired variants, and global mutation signatures and pathway analyses. Results were classified into tiers and presented to a multidisciplinary tumor board. WGS results helped to clarify an uncertain histopathological diagnosis in one case, led to informed or supported prognosis in two cases, leading to de-escalation of therapy in one, and indicated potential treatments in all eight. Overall 26 different tier 1 potentially clinically actionable findings were identified using WGS compared with six SNVs/indels using routine targeted NGS. These initial results demonstrate the potential of WGS to inform future diagnosis, prognosis, and treatment choice in cancer and justify the systematic evaluation of the clinical utility of WGS in larger cohorts of patients with cancer.

[Supplemental material is available for this article.] 


\section{INTRODUCTION}

Recent international research programs have provided a comprehensive catalog of the genomic landscape of cancer and provided insights into the temporal and spatial heterogeneity of tumors. These studies used high-throughput next-generation sequencing technology (HTS) to reveal single-nucleotide variants (SNVs) and small indels (Pleasance et al. 2010a,b; Banerji et al. 2012; The Cancer Genome Atlas Network 2012; Curtis et al. 2012; Ellis et al. 2012; Shah et al. 2012; Stephens et al. 2012) in protein-coding regions that comprise $<1 \%$ of the human genome. The clinical utility and cost-effectiveness of targeted next-generation sequencing (TGS) cancer panel testing to detect somatically acquired single gene mutations is now established in specific disease areas, such as lung and melanoma (Hamblin et al. 2017), and are illustrated by the efficacy of a number of therapeutics targeting the protein products of specific genes that are altered in human cancer. Molecular alterations have also been shown to have predictive and/or prognostic implications (Amado et al. 2008; Parsons et al. 2008).

However, the breadth and significance of various mutation types across multiple genes affecting biological pathways relevant to cancer and their potential clinical significance are largely unexplored. Whole-genome sequencing (WGS) can provide a comprehensive assessment of the mutational spectra of cancers across the entire genome. Those that may be of particular clinical relevance can be divided into five broad, evidence-based areas of analysis.

The first comprises mutations in untranslated, intronic, and intergenic regions. Common inherited variants conferring susceptibility to human disease are found frequently in noncoding regulatory or intronic regions. The possibility that similar mechanisms operate somatically in cancer was highlighted by the discovery of potentially targetable somatic driver substitutions in the TERT gene promoter (Huang et al. 2013; Vinagre et al. 2013; Khurana et al. 2016; Smith et al. 2016) and more recently in NOTCH1 splice region and a PAX5 enhancer (Puente et al. 2015).

The second area (Lin et al. 2013) addresses complex types of mutations such as copynumber aberrations (CNAs) and translocations that have not been integrated systematically with SNV analyses and linked to clinical outcome or response to therapy such as CN losses and/or SNVs involving the TP53 locus at 17p13.1 in chronic lymphocytic leukemia (Zenz et al. 2010; Dreger et al. 2013; te Raa et al. 2013) and translocations (Manolov and Manolova 1972; Rowley 1973; Dalla-Favera et al. 1982; Larson et al. 1984; Shtivelman et al. 1985; Dreazen et al. 1987; Parker and Zhang 2013).

The third set of analyses includes the comprehensive investigation of molecular pathways such as DNA damage response (DDR) pathways. All cells rely on multiple DDR pathways specialized in the repair of specific forms of DNA damage. Genes involved in these DDR pathways are among the most frequently mutated genes in cancer. Whereas a defect in a single DDR pathway is compatible with cell viability, a combination of defects in two DDR pathways leads to cell death, a concept known as synthetic lethality. Synthetic lethality can be induced by small-molecule drugs, and exploitation of a tumor's defective DDR pathway has been shown to be an effective therapeutic strategy. For example, synthetic lethality of BRCA1/2 mutations causing defective homologous recombination repair (HRR) is induced by cisplatin or PARP inhibition and has been confirmed in clinical trials (Fong et al. 2009; Fong et al. 2010; Ledermann et al. 2012).

Comprehensive analysis of combinations of constitutional and/or somatically acquired base substitution, indels, rearrangements, and $\mathrm{CN}$ changes across all genes involved in HRR-based DNA double-strand break repair may yield better predictors of responsiveness to drugs targeting this pathway than BRCA1/2 mutations or promoter methylation alone 
(Waddell et al. 2015). Constitutional or somatically acquired biallelic mutations in a number of genes associated with DDR have been defined recently and evaluated prospectively in clinical trials (Mateo et al. 2015; Pritchard et al. 2016). In particular, somatic and germline mutations in ATM, ATR, PTEN, PALB2, RAD51C, RAD50, TP53, CHEK2, BRIP1, FANCA, HDAC2, MLH3, ERCC3, MRE11, and NBN have been associated with synthetic lethality after treatment with PARP inhibitors and other emerging potential therapeutics (Riabinska et al. 2013; Dietlein et al. 2014; Mateo et al. 2015; Kristeleit et al. 2016). Furthermore, in addition to HRR and MMR, other DDR key pathways are now being targeted in the clinic (Pritchard et al. 2016; Stover et al. 2016). The fourth area involves investigating global measures such as the absolute mutational burden and mutation signatures. These measures are not routinely investigated in the clinical setting yet but can point to particular subtypes of cancer with defective mismatch repair that are associated with favorable prognosis (Tan et al. 2008; Alexandrov et al. 2013a,b; Maccaroni et al. 2015; Nik-Zainal et al. 2016) and may benefit from immune checkpoint inhibition (Heemskerk et al. 2013; Chabanon et al. 2016). Recent studies have demonstrated a direct relationship between exonic mutational burden, durable sensitivity to PD-1 and CTLA-4 blockade, and overall survival (Santin et al. 2015; McGranahan et al. 2016; Strickland et al. 2016).

The fifth and final approach includes the systematic analysis of targetable germline variants and integration with somatic variant calling in all patients with cancer rather than limiting analysis to patients with a Mendelian pattern of inheritance and early onset. This avenue is important as (1) most targeted clinical cancer sequencing does not include analysis of the germline and (2) the "first hit" of cancer pathogenesis might be present in the germline and will be subtracted during routine whole-exome sequencing (WES) or WGS tumor bioinformatics analysis, so that biallelic mutations, such as those in DDR pathways described above, will be missed.

Although WES can identify many of the mutation types described above, not all known cancer driver genes are captured by this technique and identification of complex rearrangements and copy-number abnormalities, particularly those involving noncoding regions, may not be detected. WGS allows the robust detection of all mutation types including complex somatically acquired changes. Although the feasibility of WGS in the clinical management of cancer patients has been described previously (Laskin et al. 2015), there are currently no published studies evaluating the utility of WGS in the clinical management of cancer patients beyond the detection of clinically actionable single gene variants. The aim of our study was to utilize WGS to comprehensively profile affected molecular pathways and global mutation signatures that would pinpoint clinically actionable events in patients with advanced cancers.

\section{RESULTS}

\section{Overview}

This study describes the clinically actionable mutations arising from WGS of the first eight consecutive patients recruited to a clinical genome sequencing program in the UK. The clinical characteristics of each case are described in Table 1 and the corresponding histology images are shown in Figure 1.

A summary of the total number of somatic SNVs, CNAs, and SVs and a breakdown of these variants by the tier 1,2,3 classification system for each of the cases (1-8) is shown in Supplemental Table S1. These results show that the total number of somatic mutations per case is very variable, with two cases (Cases 5 and 7) demonstrating a hypermutated genotype as described below. 


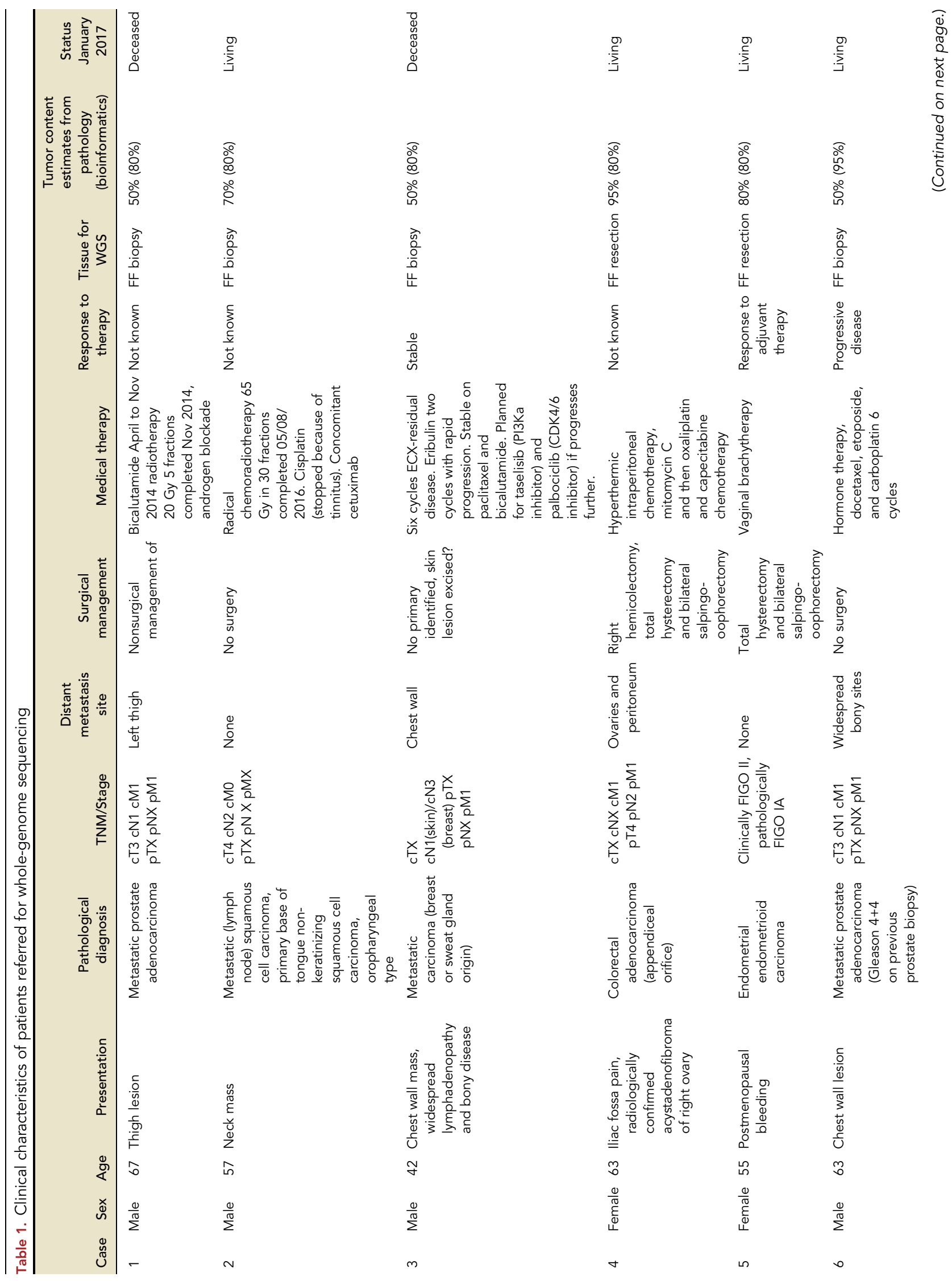




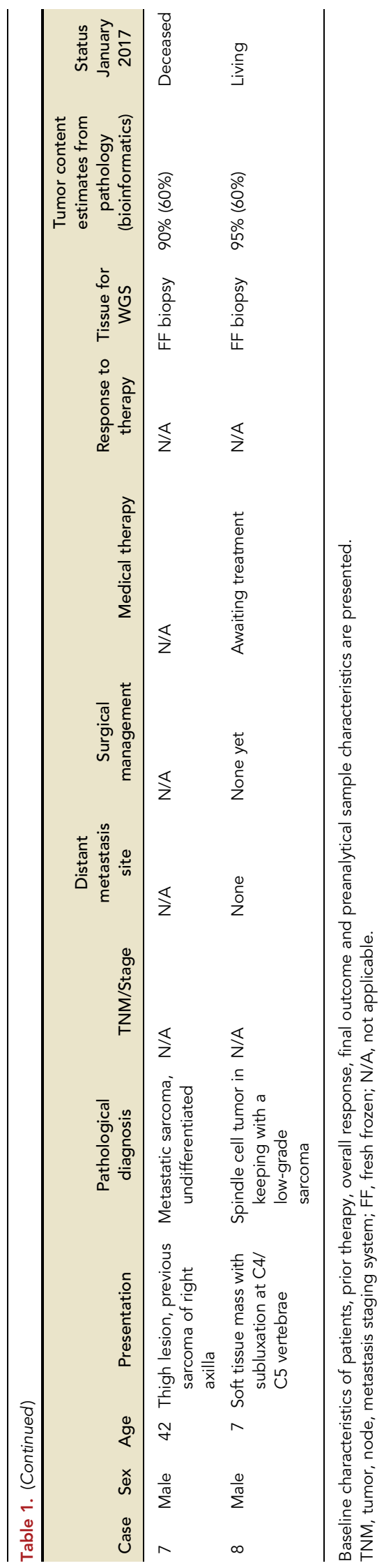




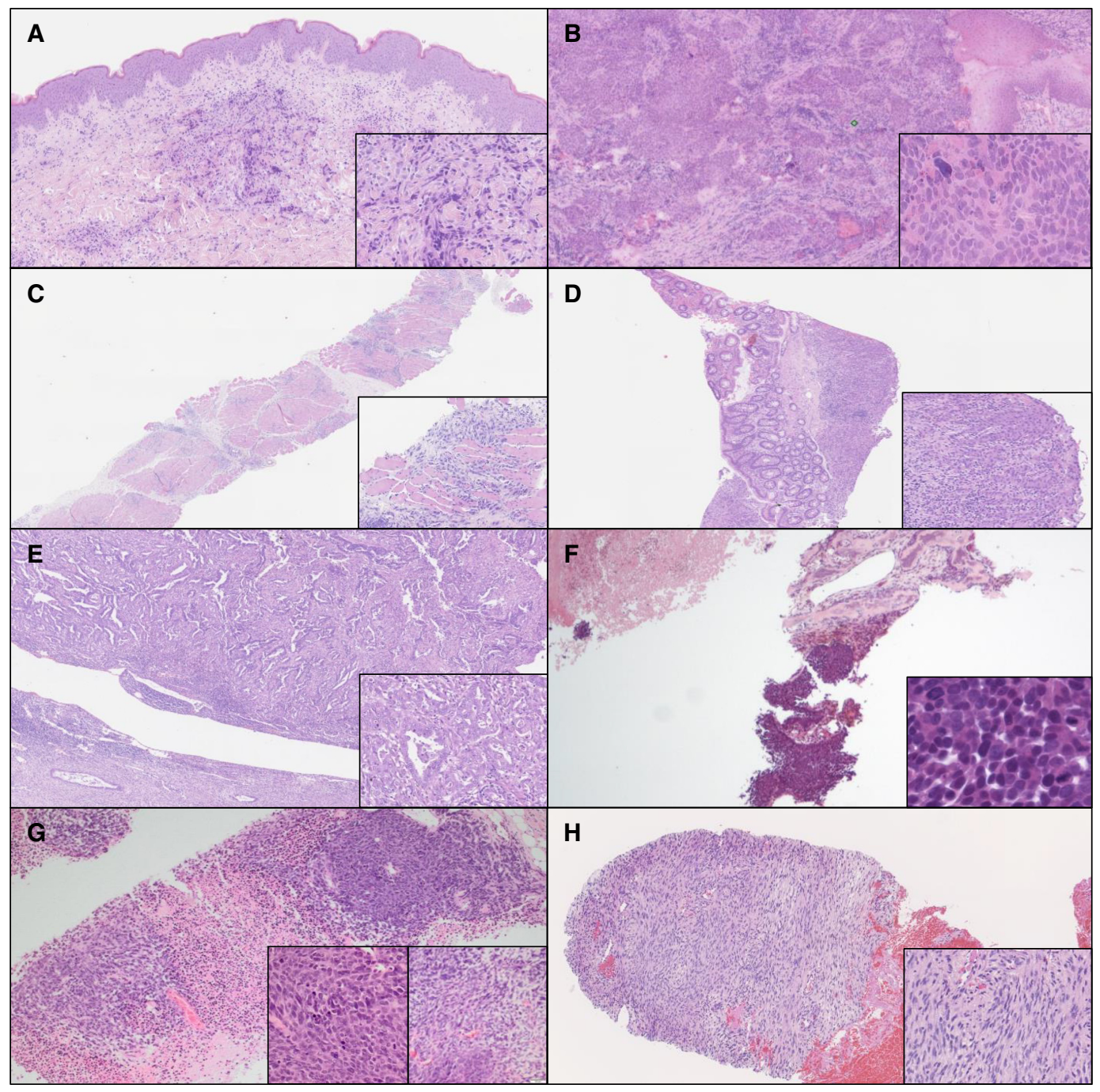

Figure 1. Histology of each tumor sequenced. Histology images of tumors resected or biopsied from Cases 1-8; sections were obtained from formalin-fixed, paraffin-embedded tissue stained with hematoxylin and eosin (H\&E). A-E and $H$ were scanned at $\times 200, F$ and $G$ were photographed at $\times 100$ and $\times 40$, respectively. (A) Case 1: Skin biopsy showing infiltration of the dermis (center) by a poorly defined tumor. (Inset) High magnification showing poorly differentiated carcinoma cells. (B) Case 2: Oral biopsy showing normal area of oral mucosa (upper right) with infiltration of the subepithelial tissue by tumor. (Inset) High magnification demonstrating a squamous cell carcinoma morphology with a lack of keratinization. (C) Case 3: Chest wall core biopsy showing skeletal muscle with widespread tumor invasion. (Inset) High magnification showing poorly differentiated carcinoma cells dissecting muscle bundles and infiltrating surrounding tissue. (D) Case 4: Cecal biopsy showing normal columnar epithelium (upper left) and an area of tumor (right). (Inset) High magnification showing poorly differentiated adenocarcinoma. (E) Case 5: Endometrial resection tissue demonstrating a large poloidal mass filling the uterine cavity with showing glandular and papillary areas. Background endometrium below. (Inset) High magnification showing the mixed appearance of the tumor. $(F)$ Case 6: Rib biopsy at low magnification showing partially necrotic bone and cartilage (upper left) and cartilage infiltrated by a high grade tumor (central). (Inset) High magnification demonstrating neuroendocrine (small cell) differentiation. (G) Case 7: Left thigh core biopsy at low magnification showing inflamed and necrotic tissue with islands of poorly differentiated tumor. (Inset, left) High magnification demonstrating the dominant epithelioid appearance of the tumor. (Inset, right) High magnification of a spindle cell component also present. $(H)$ Case 8: Cervical vertebral tumor biopsy at low magnification showing a highly cellular and poorly differentiated tumor. (Inset) High magnification showing the spindle cell morphology. 
The actionable variants and the corresponding clinical implications are described in detail for Cases 1-8 below and summarized in Tables 2 and 3, respectively. It was particularly noticeable that the SNVs and CNAs in DDR genes provided future treatment options for four cases (Fig. 2).

As expected, the mutation burden was found to be higher in introns than in exons (Supplemental Fig. 1). The somatic mutations derived from the WGS data allowed mutational signatures to be classified (Supplemental Table S2; Alexandrov et al. 2013a) and helped to identify the mutational processes operative in each patient (Fig. 3).

The majority of clinically actionable variants were somatic. Targeted in silico germline analysis of a predefined list of cancer predisposition genes (Supplemental Table S3) led to identification of multiple germline variants of uncertain significance (data not shown). One germline variant in RAD51B (Case 4) contributed to a homozygous impairment of a DDR locus and was therefore considered clinically actionable.

One anticipated advantage of using WGS is the ability to identify a spectrum of variants affecting noncoding regions. We used ENCODE databases (Supplemental Table S4) to annotate variants in regulatory regions (Supplemental Table S5), although none was considered to be clinically actionable on the basis of current knowledge.

The results for each patient are described in more detail below.

\section{CASE 1 (Prostate Cancer)}

A 67-yr-old man with a known history of prostate cancer was referred with an unusual cutaneous tumor of the left thigh (Table 1). The histology of this lesion showed a dermal infiltrate of poorly differentiated carcinoma cells (Fig. 1A) that demonstrated polyclonal prostate-specific antigen (PSA) and prostate-specific acid phosphatase (PSAP) expression by immunohistochemistry (IHC). CDX2, cytokeratin (CK) 7, and CK20 markers were negative. These findings were consistent with a prostatic origin.

The metastatic skin lesion was incompletely excised and the patient received bicalutamide from April to November 2014 combined with radiotherapy of 20 Gy in five fractions. Conventional androgen blockade commenced in January 2015. He received docetaxel chemotherapy from June to November 2015 and enzalutamide from January to February 2016.

\begin{tabular}{|c|c|c|c|c|c|c|c|c|c|}
\hline Case & $\begin{array}{l}\text { Cancer } \\
\text { type }\end{array}$ & Tier & Gene & $\begin{array}{l}\text { Mutation } \\
\text { type }\end{array}$ & $\begin{array}{l}\text { VAF } \\
(\%)\end{array}$ & $\begin{array}{l}\text { Somatic/ } \\
\text { germline } \\
\text { mutation }\end{array}$ & Location & DNA change & Protein change \\
\hline \multirow[t]{5}{*}{1} & Prostate & 1 & SETD2 & SNV & 23.33 & S & Chr 3:47129738 & $\begin{array}{l}\text { NM 014159.6: } \\
\text { c. } 5143-1 \mathrm{G}>\mathrm{A}\end{array}$ & \\
\hline & & & PTEN & CNA & - & S & Chr 10:89590587-90376982 & Loss & $\mathrm{N} / \mathrm{A}$ \\
\hline & & & TP53 & SNV & 36.89 & S & Chr 17:7577106 & $\begin{array}{l}\text { NM_000546.5: } \\
\text { c.832C >A }\end{array}$ & $\begin{array}{l}\text { NP_000537.3: } \\
\text { p.Pro278Thr }\end{array}$ \\
\hline & & & & $\mathrm{cnLOH}$ & - & S & Chr 17:0-13533148 & Allelic Imbalance & \\
\hline & & 2 & BRCA2 & $\mathrm{cnLOH}$ & - & S & Chr 13:18351244-115169878 & Allelic imbalance & $\mathrm{N} / \mathrm{A}$ \\
\hline \multirow[t]{4}{*}{2} & Oral & 1 & TP53 & None & - & N/A & $\mathrm{N} / \mathrm{A}$ & $\mathrm{N} / \mathrm{A}$ & N/A \\
\hline & & & EGFR & None & - & N/A & N/A & $N / A$ & N/A \\
\hline & & 2 & Multiple & CNA & - & $\mathrm{S}$ & Complex molecular karyotype & N/A & N/A \\
\hline & & & DDX3X & SNV & 47.06 & $S$ & Chr X:41198295 & $\begin{array}{l}\text { NM_001356.3: } \\
\text { c.107_108ins GC }\end{array}$ & $\begin{array}{l}\text { NP_001347.3: } \\
\text { p.Tyr38 AlafsTer } 7\end{array}$ \\
\hline 3 & Breast/skin & 1 & PIK3CA & SNV & 14.49 & $S$ & Chr 3:178936091 & $\begin{array}{c}\text { NM_006218.2: } \\
\text { c. } 1633 \mathrm{G}>\mathrm{C}\end{array}$ & $\begin{array}{l}\text { NP_006209.2: } \\
\text { p.Glu545Gln }\end{array}$ \\
\hline
\end{tabular}


Table 2. (Continued)

\begin{tabular}{|c|c|c|c|c|c|c|c|c|c|}
\hline Case & $\begin{array}{l}\text { Cancer } \\
\text { type }\end{array}$ & Tier & Gene & $\begin{array}{l}\text { Mutation } \\
\text { type }\end{array}$ & $\begin{array}{l}\text { VAF } \\
(\%)\end{array}$ & $\begin{array}{l}\text { Somatic/ } \\
\text { germline } \\
\text { mutation }\end{array}$ & Location & DNA change & Protein change \\
\hline & & & TP53 & Indel & 22.32 & $\mathrm{~S}$ & Chr 17:7578211 & $\begin{array}{c}\text { NM_000546.5: } \\
\text { c.638G >A }\end{array}$ & $\begin{array}{l}\text { NP_000537.3: } \\
\text { p.Arg213Gln }\end{array}$ \\
\hline & & & & Indel & 11.76 & $\mathrm{~S}$ & Chr 17:7577085 & $\begin{array}{l}\text { NM_000546.5: } \\
\text { c. } 853 G>A\end{array}$ & $\begin{array}{l}\text { NP_000537.3: } \\
\text { p.Glu285Lys N/A }\end{array}$ \\
\hline & & & & $\mathrm{cnLOH}$ & - & $\mathrm{S}$ & Chr 17:1-81195210 & Allelic imbalance & N/A \\
\hline & & 2 & BRCA1 & $\mathrm{cnLOH}$ & - & $\mathrm{S}$ & Chr 17:1-81195210 & Allelic imbalance & $N / A$ \\
\hline & & & BRIP1 & $\mathrm{cnLOH}$ & - & $\mathrm{S}$ & Chr 17:1-81195210 & Allelic imbalance & \\
\hline & & & RAD51C & $\mathrm{cnLOH}$ & - & $\mathrm{S}$ & Chr 17:1-81195210 & Allelic imbalance & \\
\hline & & & RAD51D & $\mathrm{cnLOH}$ & - & $\mathrm{S}$ & Chr 17:1-81195210 & Allelic imbalance & \\
\hline & & & FANCA & CNA & - & $S$ & Chr 16:46497599-90354753 & Loss & N/A \\
\hline \multirow[t]{7}{*}{4} & Colorectal & 1 & ARID1A & SNV & 24.36 & $\mathrm{~S}$ & Chr 1:27101198 & $\begin{array}{c}\text { NM } 006015.4: \\
\text { c. } 4480 C>T\end{array}$ & $\begin{array}{l}\text { NP_006006.3.3: } \\
\text { p.Gln1494Ter }\end{array}$ \\
\hline & & & RAD51B & SNV & 28.57 & GL & Chr 14:69061259 & $\begin{array}{c}\text { NM_133509.3.1: } \\
\text { c.1094C>G }\end{array}$ & $\begin{array}{l}\text { NP_598193.2: } \\
\text { p.Pro365Arg N/A }\end{array}$ \\
\hline & & & & CNA & - & $\mathrm{S}$ & Chr 14:68290373-69279891 & Loss & N/A \\
\hline & & & TP53 & CNA & - & $\mathrm{S}$ & Chr 17:6934163-8217978 & Loss & $\mathrm{N} / \mathrm{A}$ \\
\hline & & 2 & HDAC2 & CNA & - & $\mathrm{S}$ & Chr 6:112939290-132327952 & Loss & $\mathrm{N} / \mathrm{A}$ \\
\hline & & & SMAD4 & SNV & 8.20 & $\mathrm{~S}$ & Chr 18:48604788 & $\begin{array}{l}\text { NM 005359.5: } \\
\text { c. } 1610 A>G\end{array}$ & $\begin{array}{l}\text { NP_005350.1: } \\
\text { p.Asp537Gly }\end{array}$ \\
\hline & & & NFE2L2 & SNV & 7.52 & $\mathrm{~S}$ & Chr 2:178098954 & $\begin{array}{c}\text { NM 006164.4: } \\
\text { c. } 91 \mathrm{G}>\mathrm{A}\end{array}$ & $\begin{array}{l}\text { NP_6155.2: } \\
\text { p.Gly31Arg }\end{array}$ \\
\hline \multirow[t]{4}{*}{5} & Endometrial & 1 & TP53 & None & - & $\mathrm{S}$ & $\mathrm{N} / \mathrm{A}$ & $\mathrm{N} / \mathrm{A}$ & N/A \\
\hline & & & POLE & SNV & 34.07 & $\mathrm{~S}$ & Chr 12:133253184 & $\begin{array}{l}\text { NM_006231.2: } \\
\text { c. } 857 \mathrm{C}>\mathrm{G}\end{array}$ & $\begin{array}{l}\text { NP_006222.2: } \\
\text { p.Pro286Arg }\end{array}$ \\
\hline & & & & SNV & 37.50 & $\mathrm{~S}$ & Chr 12:133252045 & $\begin{array}{c}\text { NM_006231.2: } \\
\text { c. } 1165 T>G\end{array}$ & $\begin{array}{l}\text { NP_006222.2: } \\
\text { p.Phe389Val }\end{array}$ \\
\hline & & & Multiple & SNV & - & $\mathrm{S}$ & Tumor Mutation Burden & $\begin{array}{l}\text { Hypermutated } \\
\text { phenotype }\end{array}$ & N/A \\
\hline \multirow[t]{7}{*}{6} & Prostate & 1 & PTEN & CNA & - & $\mathrm{S}$ & Chr 10:85557432-105804295 & Loss & $N / A$ \\
\hline & & & CDKN2A & CNA & - & $\mathrm{S}$ & Chr 9:10320113-26205565 & Loss & $\mathrm{N} / \mathrm{A}$ \\
\hline & & & TP53 & SNV & 58.82 & $\mathrm{~S}$ & Chr 17:7573975 & $\begin{array}{r}\text { NM_000546.5: } \\
\text { c.1044_1051 }\end{array}$ & $\begin{array}{l}\text { NP_000537.3: } \\
\text { p.Glu349GlyfsTer30 }\end{array}$ \\
\hline & & & & CNA & - & $\mathrm{S}$ & Chr 17:7506837-7671804 & delGGAACTCA & N/A \\
\hline & & & BRCA2 & CNA & - & $\mathrm{S}$ & Chr 13:32178877-33860144 & Loss (homozygous) & $\mathrm{N} / \mathrm{A}$ \\
\hline & & 2 & FANCA & CNA & - & $\mathrm{S}$ & Chr 16:46455960-90354753 & Loss & $N / A$ \\
\hline & & & ERCC3 & CNA & - & $\mathrm{S}$ & Chr 2:104172062-168223828 & Loss & $\mathrm{N} / \mathrm{A}$ \\
\hline \multirow[t]{6}{*}{7} & Sarcoma & 1 & NRAS & SNV & 96.49 & $\mathrm{~S}$ & Chr 1:115256530 & $\begin{array}{l}\text { NM } 002524.4: \\
\text { c. } 181 \mathrm{C}>\mathrm{A}\end{array}$ & $\begin{array}{c}\text { NP_002515.1: } \\
\text { p.Gln61Lys }\end{array}$ \\
\hline & & & CDKN2A & CNA & - & $\mathrm{S}$ & Chr 9:21879074-22096083 & Loss (homozygous) & N/A \\
\hline & & & PTEN & CNA & - & $\mathrm{S}$ & Chr 10:42347406-135534747 & Loss & $\mathrm{N} / \mathrm{A}$ \\
\hline & & & Multiple & SNV & - & $\mathrm{S}$ & Tumor Mutation Burden & $\begin{array}{l}\text { Hypermutated } \\
\text { phenotype }\end{array}$ & $\mathrm{N} / \mathrm{A}$ \\
\hline & & & NF1 & CNA & - & $\mathrm{S}$ & Chr 17:25248166-30645676 & Loss & $\mathrm{N} / \mathrm{A}$ \\
\hline & & 2 & Multiple & CNA & - & $\mathrm{S}$ & Complex molecular karyotype & $\mathrm{N} / \mathrm{A}$ & $\mathrm{N} / \mathrm{A}$ \\
\hline \multirow[t]{4}{*}{8} & Soft Tissue & 1 & CDKN2A & CNA & - & $\mathrm{S}$ & Chr 9:21939408-22706613 & Loss (homozygous) & $\mathrm{N} / \mathrm{A}$ \\
\hline & & & PTEN & CNA & - & $\mathrm{S}$ & Chr 10:1-135534747 & Loss & $\mathrm{N} / \mathrm{A}$ \\
\hline & & & TSC1 & CNA & - & $\mathrm{S}$ & Chr 9:135377559-141213431 & Loss & $\mathrm{N} / \mathrm{A}$ \\
\hline & & 2 & BRCA2 & CNA & - & $\mathrm{S}$ & Chr 13:24080918-3436,992 & Loss & $\mathrm{N} / \mathrm{A}$ \\
\hline
\end{tabular}

Details of the tier 1 and tier 2 clinically actionable variants identified in Cases 1-8 are presented. The term allelic imbalance was ascribed when the BAF plots clearly revealed an acquired event, but interpretation of the $\log _{2} R$ plot was challenging (e.g., cnLOH vs. CN Loss). Such events were classified as "not clinically actionable." For cases with a hypermutated genotype (Cases 5 and 7) only clearly actionable SNVs were included.

SNV, single-nucleotide variant; indel, insertion/deletion; CNA, copy-number aberration; cnLOH, copy neutral loss of heterozygosity; SV, structural variant; S, somatic; GL, germline. 
Table 3. Clinical significance of actionable variants

\begin{tabular}{|c|c|c|c|c|c|c|c|c|c|}
\hline Case & $\begin{array}{l}\text { Cancer } \\
\text { type }\end{array}$ & Tier & Gene & $\begin{array}{l}\text { Mutation } \\
\text { Type }\end{array}$ & $\begin{array}{l}\text { Somatic/ } \\
\text { germline } \\
\text { mutation }\end{array}$ & Pathway & $\begin{array}{c}\text { Clinical } \\
\text { significance of } \\
\text { mutation }\end{array}$ & $\begin{array}{l}\text { Potential clinical } \\
\text { trials }\end{array}$ & $\begin{array}{l}\text { MDT decision/Impact on } \\
\text { clinical management }\end{array}$ \\
\hline \multirow[t]{4}{*}{1} & \multirow[t]{4}{*}{ Prostate } & \multirow[t]{3}{*}{1} & SETD2 & SNV & $S$ & $\begin{array}{l}\text { Chromatin } \\
\text { remodelling }\end{array}$ & $\begin{array}{l}\text { Therapy (WEE } \\
\text { inhibitors) }\end{array}$ & $\begin{array}{l}\text { NCT01748825 (solid } \\
\text { tumors) } \\
\text { NCT02341456 (solid } \\
\text { tumors) } \\
\text { NCT02585973 (head } \\
\text { and neck cancer) }\end{array}$ & \multirow[t]{4}{*}{$\begin{array}{l}\text { Patient died before WGS } \\
\text { completed, but PARP/ } \\
\text { WEE inhibitors may } \\
\text { have been an option. }\end{array}$} \\
\hline & & & PTEN & CNA & $S$ & $\begin{array}{l}\text { PTEN-AKT1- } \\
\text { mTOR } \\
\text { pathway }\end{array}$ & $\begin{array}{l}\text { Poor prognosis, } \\
\text { therapy } \\
\text { (mTOR, PARP } \\
\text { inhibitors) }\end{array}$ & $\begin{array}{l}\text { NCT02145559 (solid } \\
\text { tumors) } \\
\text { NCT02465060 ( NCl } \\
\text { match) }\end{array}$ & \\
\hline & & & TP53 & $\begin{array}{l}\text { SNV } \\
\text { cnLOH }\end{array}$ & $\begin{array}{l}S \\
S\end{array}$ & $\begin{array}{l}\text { DDR } \\
\text { DDR }\end{array}$ & $\begin{array}{l}\text { Poor prognosis, } \\
\text { therapy } \\
\text { (PARP } \\
\text { inhibitors) }\end{array}$ & $\begin{array}{l}\text { NCT02098343 } \\
\text { (ovarian cancer) }\end{array}$ & \\
\hline & & 2 & BRCA2 & $\mathrm{cnLOH}$ & $S$ & DDR & $\begin{array}{l}\text { Therapy (PARP } \\
\text { inhibitors) }\end{array}$ & $\begin{array}{l}\text { NCT03040791 } \\
\text { (DDR-impaired } \\
\text { prostate cancer) } \\
\text { NCT03012321 } \\
\text { (DDR-impaired } \\
\text { prostate cancer) }\end{array}$ & \\
\hline \multirow[t]{4}{*}{2} & \multirow[t]{4}{*}{ Oral } & 1 & TP53 & None & $N / A$ & N/A & Therapy & N/A & \multirow{4}{*}{$\begin{array}{l}\text { HPV +ve indicative of } \\
\text { good prognosis. } \\
\text { Standard of care was } \\
\text { applied. Lack of DDR } \\
\text { signature (please see } \\
\text { text) and EGFR } \\
\text { mutations supported } \\
\text { cessation of cisplatin } \\
\text { and commencement of } \\
\text { cetuximab, respectively }\end{array}$} \\
\hline & & & EGFR & None & $\mathrm{N} / \mathrm{A}$ & $\mathrm{N} / \mathrm{A}$ & & & \\
\hline & & & Multiple & CNA & S & Multiple & $\begin{array}{l}\text { Pathological } \\
\text { classification }\end{array}$ & $\mathrm{N} / \mathrm{A}$ & \\
\hline & & 2 & $D D X 3 X$ & SNV & $S$ & $\begin{array}{l}\text { RNA } \\
\text { metabolism }\end{array}$ & $\begin{array}{l}\text { Pathological } \\
\text { classification, } \\
\text { therapy } \\
\text { (histone } \\
\text { methylation) }\end{array}$ & N/A & \\
\hline \multirow[t]{8}{*}{3} & \multirow[t]{8}{*}{ Breast/Skin } & 1 & PIK3CA & SNV & $S$ & $\begin{array}{l}\text { PIK3CA } \\
\text { signaling }\end{array}$ & $\begin{array}{c}\text { Therapy (PI3K } \\
\text { inhibitors) }\end{array}$ & $\begin{array}{l}\text { NCT02389842 } \\
\text { (breast and solid } \\
\text { tumors) } \\
\text { NCT01226316 } \\
\text { (breast and solid } \\
\text { tumors) } \\
\text { NCT02437318 } \\
\text { (breast cancer) } \\
\text { NCT02423603 } \\
\text { (breast cancer) } \\
\text { NCT01872260 } \\
\text { (breast cancer) } \\
\text { NCT02088684 } \\
\text { (breast cancer) } \\
\text { NCT02465060 (NCl } \\
\text { match) }\end{array}$ & \multirow[t]{8}{*}{$\begin{array}{l}\text { Standard of care was } \\
\text { applied. Treatment with } \\
\text { PI3K or PARP inhibitors } \\
\text { proposed in event of } \\
\text { disease progression. } \\
\text { Patient died rapidly } \\
\text { because of disease } \\
\text { progression before such } \\
\text { therapies initiated. }\end{array}$} \\
\hline & & & TP53 & SNV & S & DDR & Poor prognosis, & NCT02098343 & \\
\hline & & & & SNV & $\mathrm{S}$ & DDR & therapy & (ovarian cancer) & \\
\hline & & & & $\mathrm{cnLOH}$ & S & DDR & $\begin{array}{l}\text { (PARP } \\
\text { inhibitors) }\end{array}$ & $\begin{array}{l}\text { NCT01074970 } \\
\text { (breast cancer) }\end{array}$ & \\
\hline & & 2 & BRCA1 & $\mathrm{cnLOH}$ & S & DDR & Therapy (PARP & & \\
\hline & & & BRIP1 & $\mathrm{cnLOH}$ & S & DDR & inhibitors) & & \\
\hline & & & RAD51C & $\mathrm{cnLOH}$ & S & DDR & & & \\
\hline & & & RAD51D & $\mathrm{cnLOH}$ & $S$ & DDR & & & \\
\hline
\end{tabular}


Table 3. (Continued)

\begin{tabular}{|c|c|c|c|c|c|c|c|c|c|}
\hline Case & $\begin{array}{l}\text { Cancer } \\
\text { type }\end{array}$ & Tier & Gene & $\begin{array}{l}\text { Mutation } \\
\text { Type }\end{array}$ & $\begin{array}{l}\text { Somatic/ } \\
\text { germline } \\
\text { mutation }\end{array}$ & Pathway & $\begin{array}{c}\text { Clinical } \\
\text { significance of } \\
\text { mutation }\end{array}$ & $\begin{array}{c}\text { Potential clinical } \\
\text { trials }\end{array}$ & $\begin{array}{l}\text { MDT decision/Impact on } \\
\text { clinical management }\end{array}$ \\
\hline & & & FANCA & CNA & $S$ & DDR & $\begin{array}{l}\text { Therapy (PARP } \\
\text { inhibitors) }\end{array}$ & $\begin{array}{l}\text { NCT03012321 } \\
\text { (Prostate cancer) }\end{array}$ & \\
\hline \multirow[t]{7}{*}{4} & Colorectal & 1 & ARID1A & SNV & S & $\begin{array}{l}\text { Chromatin } \\
\text { remodelling }\end{array}$ & $\begin{array}{l}\text { Therapy } \\
\text { (Dasatinib; } \\
\text { AKT inhibitor; } \\
\text { EZH2 } \\
\text { inhibitor) }\end{array}$ & $\begin{array}{l}\text { NCT02059265 } \\
\text { (Ovarian cancer) } \\
\text { NCT02576444 (solid } \\
\text { tumors) }\end{array}$ & \multirow[t]{7}{*}{$\begin{array}{l}\text { Standard of care was } \\
\text { applied. Excellent } \\
\text { response to platinum } \\
\text { therapy. PARP inhibition } \\
\text { considered as an option } \\
\text { at relapse. }\end{array}$} \\
\hline & & & RAD51B & SNV & $\mathrm{GL}$ & DDR & Therapy (PARP & NCT02484404 (solid & \\
\hline & & & & & S & DDR & inhibitors) & $\begin{array}{l}\text { tumors) } \\
\text { NCT00576654 (solid } \\
\text { tumors) } \\
\text { NCT02921256 (rectal } \\
\text { cancer) }\end{array}$ & \\
\hline & & & TP53 & CNA & $S$ & DDR & $\begin{array}{l}\text { Poor prognosis, } \\
\text { therapy } \\
\text { (PARP } \\
\text { inhibitors) }\end{array}$ & $\begin{array}{l}\text { NCT02098343 } \\
\text { (ovarian cancer) }\end{array}$ & \\
\hline & & 2 & HDAC2 & CNA & S & DDR & $\begin{array}{l}\text { Therapy (PARP } \\
\text { inhibitors) }\end{array}$ & $\begin{array}{l}\text { NCT03012321 } \\
\quad \text { (prostate cancer) }\end{array}$ & \\
\hline & & & SMAD4 & SNV & S & TGF- $\beta$ signaling & $\begin{array}{l}\text { Biological } \\
\text { mechanism }\end{array}$ & N/A & \\
\hline & & & NFE2L2 & SNV & $\mathrm{S}$ & $\begin{array}{l}\text { Antioxidant } \\
\text { metabolism }\end{array}$ & $\begin{array}{l}\text { Biological } \\
\text { mechanism }\end{array}$ & $\mathrm{N} / \mathrm{A}$ & \\
\hline \multirow[t]{3}{*}{5} & Endometrial & 1 & TP53 & None & $\mathrm{S}$ & DDR & $\begin{array}{l}\text { Pathological } \\
\text { classification }\end{array}$ & $\mathrm{N} / \mathrm{A}$ & \multirow{3}{*}{$\begin{array}{l}\text { Results from WGS clarified } \\
\text { histopathological } \\
\text { classification, confirming } \\
\text { an endometrioid rather } \\
\text { than serous tumor type } \\
\text { with good prognosis. } \\
\text { Patient declined } \\
\text { chemotherapy on basis } \\
\text { of confirmatory } \\
\text { prognostic information } \\
\text { from WGS. Option of } \\
\text { checkpoint inhibitors in } \\
\text { event of disease } \\
\text { progression. }\end{array}$} \\
\hline & & & POLE & SNV & $\mathrm{S}$ & $\begin{array}{l}\text { Polymerase } \\
\text { proofreading } \\
\text { Polymerase } \\
\text { proofreading }\end{array}$ & $\begin{array}{l}\text { Therapy (anti- } \\
\text { PDL1) }\end{array}$ & $\begin{array}{l}\text { NCT02912572 } \\
\text { (endometrial } \\
\text { cancer) }\end{array}$ & \\
\hline & & & Multiple & SNV & $\mathrm{S}$ & Multiple & $\begin{array}{l}\text { Therapy (anti- } \\
\text { PDL1) }\end{array}$ & $\begin{array}{l}\text { NCT02912572 } \\
\text { (endometrial } \\
\text { cancer) }\end{array}$ & \\
\hline \multirow[t]{5}{*}{6} & Prostate & 1 & PTEN & CNA & S & $\begin{array}{l}\text { PTEN-AKT1- } \\
\text { mTOR } \\
\text { pathway }\end{array}$ & $\begin{array}{l}\text { Poor prognosis, } \\
\text { therapy } \\
\text { (mTOR } \\
\text { inhibitors) }\end{array}$ & $\begin{array}{l}\text { NCT02145559 (solid } \\
\text { tumors) } \\
\text { NCT02465060 } \\
\text { (NCl Match) }\end{array}$ & \multirow{5}{*}{$\begin{array}{l}\text { Commenced treatment } \\
\text { with PARP inhibitor } \\
\text { rucaparib } 24 \text { months } \\
\text { ago following results } \\
\text { from WGS. Still alive. } \\
\text { Clinical trial of anti-PD1 } \\
\text { inhibitor might also be } \\
\text { considered. }\end{array}$} \\
\hline & & & CDKN2A & CNA & S & $\begin{array}{l}\text { Cell cycle } \\
\text { regulator of } \\
\text { P53 }\end{array}$ & $\begin{array}{l}\text { Therapy (Aurora } \\
\text { NEGF } \\
\text { inhibitors) }\end{array}$ & $\begin{array}{l}\text { NCT02478320 (solid } \\
\text { tumors) }\end{array}$ & \\
\hline & & & TP53 & SNV & S & DDR & Poor prognosis, & NCT03040791 & \\
\hline & & & & CNA & S & DDR & $\begin{array}{l}\text { therapy } \\
\text { (PARP } \\
\text { inhibitors) }\end{array}$ & $\begin{array}{l}\text { (DDR-impaired } \\
\text { prostate cancer) } \\
\text { NCT03012321 } \\
\text { (DDR-impaired } \\
\text { prostate cancer) }\end{array}$ & \\
\hline & & & BRCA2 & CNA & S & DDR & $\begin{array}{l}\text { Therapy (PARP } \\
\text { inhibitors) }\end{array}$ & $\begin{array}{l}\text { NCT03040791 } \\
\text { (DDR-impaired } \\
\text { prostate cancer) } \\
\text { NCT03012321 }\end{array}$ & \\
\hline
\end{tabular}

(Continued on next page.) 
Table 3. (Continued)

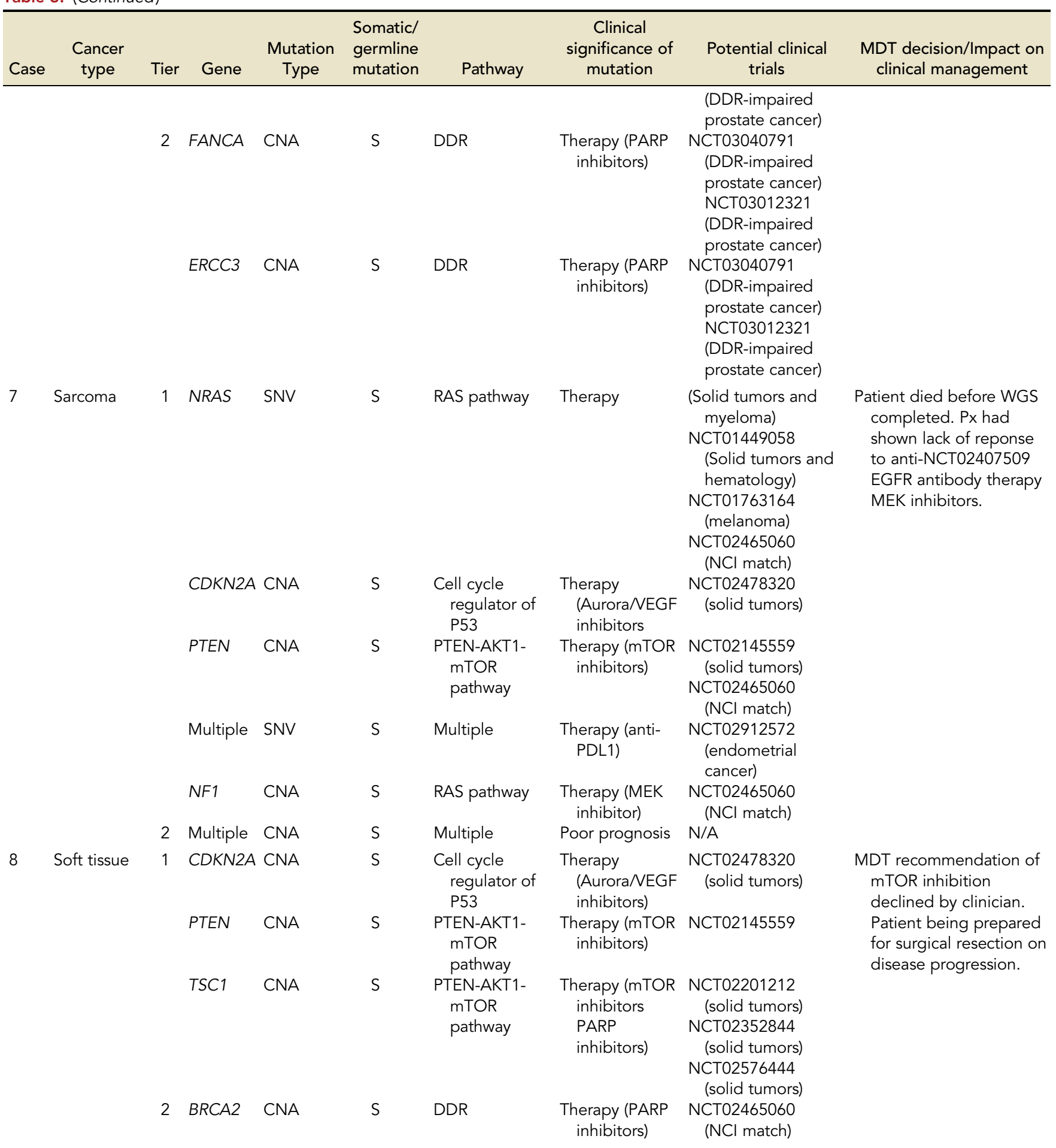

The potential clinical implications of the tier 1 and tier 2 variants described in Table 2 are shown, including impact of the variant on diagnosis, prognosis, potential treatment, or clinical trials for which the patient might be eligible. Specifically, for defects in the DDR pathway, only inferred homozygous mutations were classified as clinically actionable (highlighted by shaded background).

SNV, single-nucleotide variant; CNA, copy number aberration; cnLOH, copy neutral loss of heterozygosity; SV, structural variant; DDR, DNA damage response; S, somatic; GL, germline. 

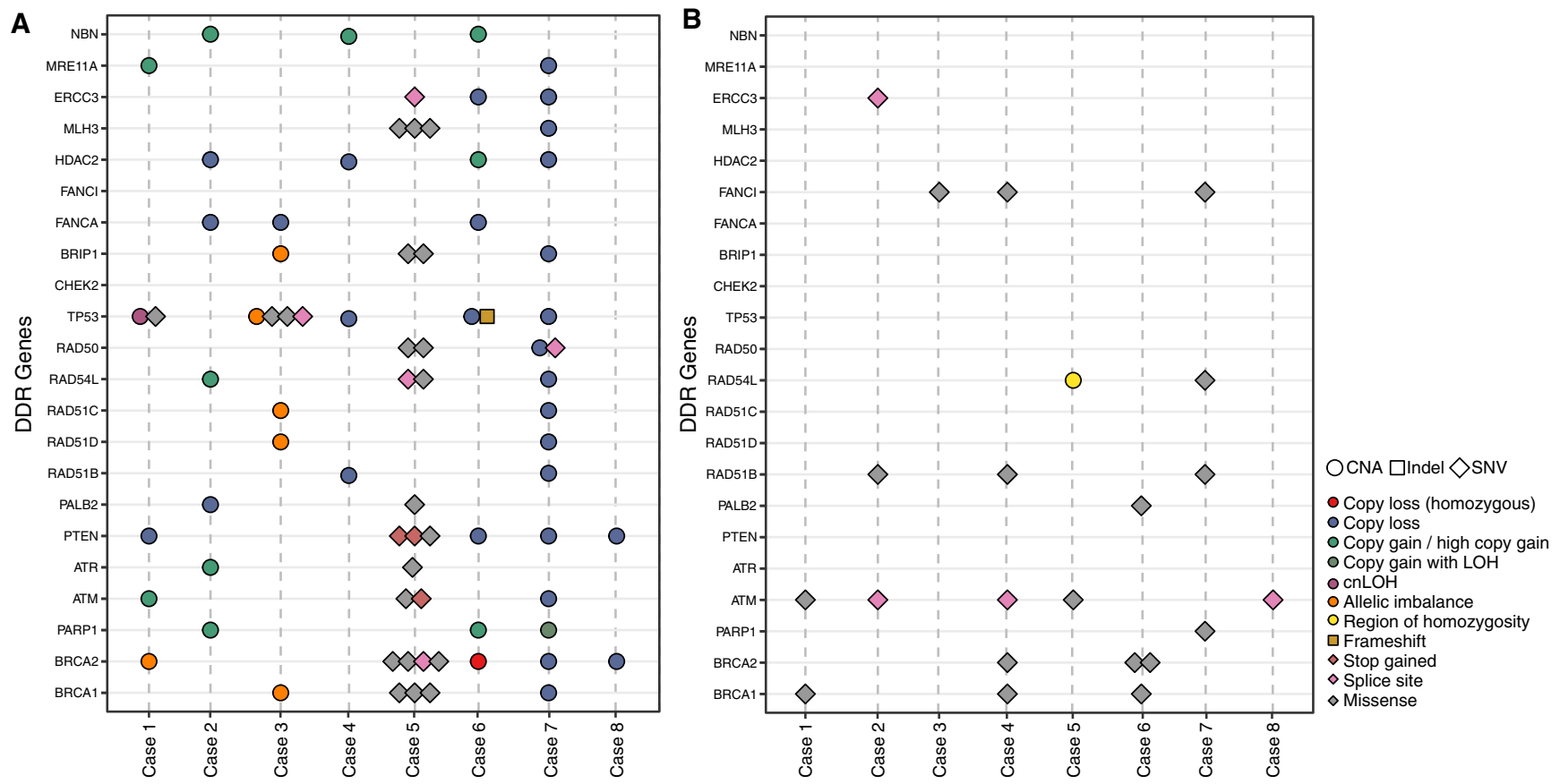

Figure 2. Identification of somatic and germline variants in genes from the DNA damage response (DDR) pathway from Cases 1-8. Graphical representation of the variants identified by WGS in 22 DDR pathway genes in cancer Cases 1-8. A and B show somatic and germline variants, respectively, for each cancer case. Each bar or track on the horizontal axis represents a different cancer case and the 22 individual DDR genes are represented on the vertical axis. CNAs, indels, and SNVs are represented by circles, squares, and diamonds, respectively. The color key indicates more detail about the type of variant (e.g., a red circle represents a homozygous copy-number loss). Only disruptive somatic or germline SNVs and indels are included, whereas for germline variants $(B)$ only SNVs with minor allele frequency of $<6 \%$ are included. Case 1 includes a somatic missense SNV and a cnLOH region involving TP53, as well as copy-number loss of PTEN and allelic imbalance of BRCA2. Case 2 presents copy-number aberrations overlapping various DDR genes, but no SNVs, indels, or copy-number events involving TP53. Case 3 includes TP53 mutations, an allelic imbalance involving TP53, BRCA1, BRIP1, RAD51C, and RAD51D, and a single loss involving FANCA. In Case 4, WGS detected a germline deleterious SNV in RAD51B, together with a somatic CN loss in the same locus. Case 5 includes somatic mutations in various DDR genes but no copy-number aberrations, whereas RAD54L and ATM in the germline are affected by a region of homozygosity and a missense mutation, respectively. Case 6 has a frameshift mutation and a CN loss involving TP53 and, importantly, a somatic homozygous CN loss encompassing BRCA2. In Case 7, most DDR genes are affected by a somatic $C N$ loss or gain, whereas the germline includes missense mutations in FANCl, RAD54L, RAD51B, and PARP1. Finally, in Case 8, PTEN and BRCA2 are affected by somatic CN losses, and ATM includes a splice site mutation in the germline. See the main text for more details.

TGS of DNA derived from the metastasis showed a variant in TP53 (c.832C>A, p.Pro278Thr), indicative of poor prognosis. WGS of paired tumor and germline DNA confirmed the somatic tier 1 SNV in TP53 and additionally revealed a $\mathrm{cnLOH}$ region of Chromosome 17 (17p13.3-p12) involving TP53, as well as copy-number loss of PTEN and allelic imbalance of BRCA2 (Table 2; Fig. 2), all genes involved in the DDR. These events presented with allelic imbalance, which was most likely explained by germline contamination as the tumor content for biopsied tissue was estimated as 50\% (Table 2; Supplemental Fig. S2). Mutation signature 5 associated with all cancer types (Alexandrov et al. 2013a) was the dominant signature from WGS data (Fig. 3). WGS also showed a SETD2 (tier 1) variant (c.5143$1 \mathrm{G}>\mathrm{A}$ ) (Table 2). Unfortunately, the patient died of progressive disease before the results of WGS were available. 


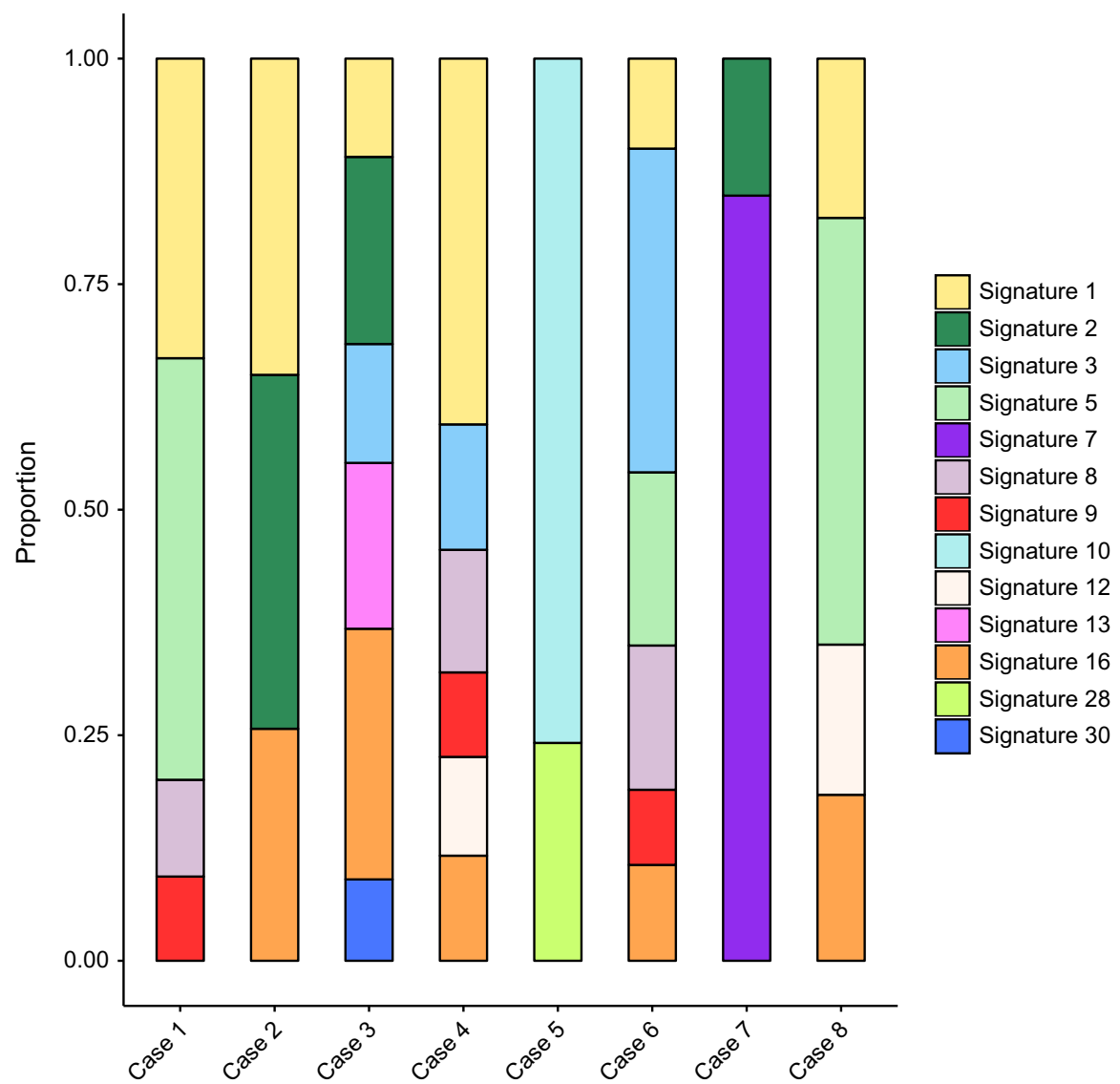

Figure 3. The proportion of mutation signatures in Cases 1-8. Mutation signatures were obtained from the COSMIC mutation signatures consensus database (http://cancer.sanger.ac.uk/COSMIC /signatures), which were derived using published methods developed by Alexandrov et al. (2013a). Signatures represent genomic SNV distribution in a trinucleotide context. The contributions of each COSMIC signature found in the data were calculated using the deconstructSigs package (Rosenthal et al. 2016) in R. Stacked bars represent the proportion of each mutation signature found in each case across the whole genome, where all signatures found per case sum to 1. Mutation signature 1 is the most ubiquitous and represents aging. Signature 2: AID/ APOBEC association. Signature 3: BRC1/2-associated and DNA double-strand break repair defect. Signature 4: smoking. Signature 5: unknown etiology. Signature 6: DNA mismatch repair defect. Signature 7: UV exposure. Signature 8: unknown. Signature 9: polymerase-associated mutation pattern. Signature 10: associated with altered POLE activity. Signature 11: alkylating agents. Signature 12: unknown. Signature 13: AID/APOBEC association. Signature 14: unknown. Signature 15: DNA mismatch repair defect. Signatures 16, 17, 18, 19: unknown. Signature 20: DNA mismatch repair defect. Signature 21: unknown. Signature 22: exposure to aristolochic acid. Signature 23. Unknown. Signature 24: exposure to aflatoxin. Signature 25: unknown. Signature 26: DNA mismatch repair defect. Signature 27,28: unknown. Signature 29: tobacco chewing. Signature 30: unknown. More details of signatures are described in Supplemental Table S2.

\section{CASE 2 (Head and Neck Cancer)}

A 57-yr-old man presented with a large, left-sided base of tongue tumor and lymphadenopathy (Table 1). Biopsy from the oropharyngeal lesion revealed a nonkeratinizing squamous cell carcinoma (Fig. 1B). The tumor demonstrated positive staining with p16 IHC tests, in keeping with human papilloma virus (HPV) etiology and associated with a good prognosis for oropharyngeal cancer (Langendijk and Psyrri 2010).

SNV and CNA analyses of WGS data did not show any somatically acquired clinically actionable mutations (Table 2). The genome exhibited a complex karyotype, a mutation in 
DDX3X, and absence of TP53 mutations, all in keeping with HPV-positive squamous cell carcinoma (Seiwert et al. 2015). We confirmed the presence of HPV-derived sequences in the whole-genome data and identified the viral subtype (Table 3; Supplemental Materials and Methods). Presence of mutation signature 2 is consistent with the viral etiology of the tumor (Fig. 3).

The patient started radical chemoradiotherapy at 65 Gy in 30 fractions in August 2016. Following one cycle of cisplatin, he developed intractable tinnitus. Cisplatin was stopped, a decision supported by the absence of a DDR mutation signature and good prognosis features, and the patient was started on concomitant cetuximab (Table 3). Reassuringly, WGS confirmed that there were no EGFR resistance mutations to this drug. Positron-emission and computed tomography (PET-CT) imaging at 3 mo indicated no residual disease.

In this case, WGS did not demonstrate any actionable mutations. However, it confirmed the presence of HPV, which, combined with absence of TP53 mutations, indicated a good prognosis for this patient. The absence of biallelic mutations in DDR genes or in the known cancer predisposition gene EGFR assisted in managing drug side effects and in confirming the choice of an alternative targeted therapy (lida et al. 2014; Tajima and Koda 2015).

\section{CASE 3 (Breast Cancer and Melanoma)}

A 42-yr-old man with a previous history of malignant melanoma presented with a left chest wall mass and widespread lymphadenopathy (Table 1). Combined PET-CT scanning revealed disseminated disease with bony involvement. Biopsies from the chest wall lesion and overlying skin revealed a malignant tumor with an epithelioid morphology infiltrating into skeletal muscle. A bone marrow trephine biopsy (Fig. 1C) also revealed marrow space involvement. The tumor cells were immune-reactive for nonspecific epithelial markers (CAM 5.2, AE1/AE3) as well as CK7, CK19, GATA3, and GCDFP, suggesting a breast origin. The tumor did not express CK20 or CDX2 (colorectal), PSA, RCC (renal), TTF1 (lung), or melanoma markers. The suspicion was that it was of breast origin but ductal carcinoma in situ (DCIS) could not be identified in the chest wall biopsies, and a sweat gland tumor could not be excluded. Estrogen receptor (ER), progesterone receptor (PR), and Her-2/neu (ErbB-2) hormone markers were also negative by IHC tests. Based on these findings, the differential diagnosis was either a triple-negative breast (ductal) carcinoma or a malignant skin adnexal tumor. The patient commenced treatment with a standard carcinoma of unknown primary (CUP) schedule with six cycles of ECX (epirubicin, cisplatin, capecitabine/Xeloda) and showed a good clinical and radiological response. However, 3 mo later, when there was evidence of progressive chest wall disease, the patient entered a Phase II clinical trial of immunotherapy against standard of care chemotherapy. He was randomized to the control arm and received eribulin, a potent mitotic inhibitor. His disease rapidly progressed, leading to a switch to paclitaxel and bicalutamide because of strong androgen receptor expression identified by IHC tests. He achieved a complete clinical and radiological remission in the known sites of disease within 3 mo.

Because TGS and WGS showed an activating PIK3CA mutation (c.1633C>G, p.Glu545Gln), the proposed management was to proceed with the PIK3CA inhibitors, taselisib or pictilisib, at disease progression (Turner et al. 2015). In addition, WGS revealed two different acquired pathogenic TP53 mutations and an allelic imbalance reflecting either a CN loss or cnLOH involving TP53, BRCA1, BRIP1, RAD51C, and RAD51D (Fig. 2A) and a single loss of FANCA indicating PARP inhibition as a potential therapeutic avenue. Consistent with this, we identified mutation signature 3 (Fig. 3).

Similar to Case 1, this case illustrates that WGS can reveal all types of mutations in the DDR pathway. The dominant mutation signatures in this patient were signatures 16 (unknown significance), 2, and 13, whereas the DDR signature was also present. A germline 
deletion polymorphism involving APOBEC $3 A$ and $A P O B E C 3 B$ on Chromosome 22 is associated with the presence of large numbers of signature 2 and 13 mutations and with predisposition to breast cancer (Nik-Zainal et al. 2014), but this patient did not carry the germline polymorphism.

\section{CASE 4 (Colorectal Cancer)}

A 64-yr-old woman who presented with abdominal pain underwent excision of a radiologically nonsuspicious simple cyst of the right ovary (Table 1). At operation both ovaries were found to be infiltrated by solid tumor, there was a dilated right fallopian tube, and numerous widespread peritoneal deposits were observed. A bilateral salpingo-oophorectomy (BSO) was performed and the peritoneal lesions were biopsied. Histology of the ovaries and peritoneal lesions revealed a poorly differentiated carcinoma with areas of glandular and signet ring cell morphology, as well as focal neuroendocrine differentiation. The right fallopian tube was infiltrated by malignant cells and contained foci of endometriosis. The tumor cells were immune-reactive for carcinoembryonic antigen (CEA), CDX2, CK20, CK8/18, and CA19.9 IHC tests, suggesting a colorectal origin, and tested negative for markers of gynecological, breast, or other common tumors of epithelial origin (CK7, CA125, inhibin, p16, p53, WT1, PAX8, GCDPF, ER, and PR). Cytology of peritoneal washings also showed a malignant population of epithelial cells. The findings were consistent with a metastatic carcinoma of gastrointestinal (GI) origin. Endoscopic examination of the lower $\mathrm{Gl}$ tract was carried out and revealed a tumor in the cecum at the appendiceal orifice. Biopsies from this area (Fig. 1D) revealed similar histological findings with tumor appearing to arise from overlying dysplastic mucosa. The overall findings were consistent with metastatic adenocarcinoma of colorectal origin. The patient underwent right hemicolectomy and hysterectomy. The surgery left her free of visible disease and she then opted for oxaliplatin-based adjuvant chemotherapy.

TGS did not reveal any clinically actionable mutations. WGS identified a tier 1 germline deleterious SNV in RAD51B together with an acquired CN loss of this locus that could be regarded as a second hit and is consistent with impairment of the DDR signaling pathway function (Fig. 2A,B). Supporting these findings, mutation signature 3 was clearly present in this tumor (Fig. 3). Furthermore, WGS showed a tier 1 nonsense mutation in ARID1A (c.4480C $>$ T, p.Gln1494Ter). A recent study demonstrated synthetic lethality by targeting EZH2 histone methyltransferase activity in ARID1A-mutated tumors using a clinically applicable small molecule inhibitor (Bitler et al. 2015a), and a clinical trial for patients with mutations in ARID1A is now recruiting and others are planned (Bitler et al. 2015b) for which the patient could be eligible.

WGS also revealed tier 2 mutations in HDAC2, NFE2L2, and SMAD4 that are likely to have biological and prognostic significance (Table 2) but are not clinically actionable.

Importantly, this case illustrates impairment of the DDR pathway because of a combination of a germline deleterious SNV with a second acquired hit affecting RAD51B. The patient may benefit from PARP-1 inhibition should she relapse after standard care. WGS, but not TGS, also revealed a tier 1 defect in the key chromatin-remodeling gene ARID1A, supporting eligibility to potentially efficacious therapy as part of a clinical trial.

\section{CASE 5 (Endometrial Cancer)}

A 55-yr-old woman presented with postmenopausal bleeding (Table 1). Ultrasound imaging of the pelvis revealed a uterine mass. Histolopathological review of the biopsy suggested a grade 3 mixed endometrioid/serous endometrial carcinoma. Total laparoscopic hysterectomy and bilateral salphingo-ophorectomy demonstrated a polypoidal tumor in the uterine 
cavity arising from the endometrium and extending to the lower segment. The results of histopathological analysis of the resected specimen (Fig. 1E) were similar to that of the biopsy. IHC tests were difficult to interpret; ER, PAX8, and vimentin showed positivity in some areas of the tumor (in keeping with endometrioid carcinoma) but occasional foci showed strong diffuse p16 staining (usually seen in serous carcinoma). PR (endometrioid) and WT1 (serous) markers were negative. The pattern of expression was therefore mixed (Kaspar and Crum 2015). This diagnostic uncertainty was highly clinically relevant, as uterine serous carcinoma is an aggressive tumor that is typically managed with intensive adjuvant therapy, whereas endometrioid histologies are associated with a more benign course. As uterine serous carcinoma is frequently associated with the presence of TP53 mutations, molecular testing was performed to identify these and other variants useful in guiding management (SGO Clinical Practice Endometrial Cancer Working Group et al. 2014a,b). Interestingly, although neither TGS nor WGS detected any TP53 mutation, WGS demonstrated a pathogenic mutation in the exonuclease domain of the replicative DNA polymerase POLE (c.857C >G, p.Pro286Arg) (Table 2), along with the characteristic ultramutated phenotype (Supplemental Fig. S1) and dominant mutational signature 10 this causes (Fig. 3; Prindle et al. 2010; Church et al. 2014; van Gool et al. 2015). Although unexpected, this result was not entirely surprising, as POLE mutations are often associated with high tumor grade and difficulty in pathological classification (Hussein et al. 2015; van Gool et al. 2018). Despite this association, endometrial cancers carrying POLE exonuclease domain mutations are recognized to have an excellent prognosis, possibly because they are more immunogenic than other cancers (Van Gool et al. 2015). In light of the molecular data, the initial pathological impression of an aggressive serous carcinoma was revised to a much more favorable prognosis (Tashiro et al. 1997; Bansal et al. 2009; Yemelyanova et al. 2011; Church et al. 2014; Stelloo et al. 2015). The patient elected to have post-operative brachytherapy only, and did not receive the adjuvant chemotherapy and external beam radiotherapy that is the standard of care for uterine serous carcinoma. This case illustrates that WGS results can assist with clinically relevant pathological differential diagnosis and can support deescalation of therapy in line with the patient's choice (Table 3). Moreover, in the event of disease progression, POLE mutations may predict sensitivity to nivolumab or pebrolizumab (Santin et al. 2016).

\section{CASE 6 (Prostate Cancer)}

A 63-yr-old man presented with a PSA of $2900 \mu \mathrm{g} / \mathrm{ml}$ and was found to have a Gleeson $4+4$ prostatic adenocarcinoma on biopsy (Table 1). Clinical imaging revealed pulmonary and bony metastases. Despite androgen deprivation treatment, the patient progressed and there was no response to docetaxel or radiotherapy. A biopsy from a rib metastasis at this time showed neuroendocrine differentiation (Fig. 1F), and it was concluded that a smallcell carcinoma component had developed following treatment (Miyoshi et al. 2001; Lipianskaya et al. 2014; Nadal et al. 2014).

TGS performed on DNA obtained from the rib metastasis showed a pathogenic mutation in TP53. WGS confirmed the mutation and also showed a CN loss involving TP53 and, importantly, an acquired homozygous CN loss encompassing BRCA2 (Table 2; Fig. 2A). The patient had a dramatic clinical, radiological, and biochemical response following platinum-based chemotherapy (etoposide and carboplatin). At biochemical relapse, he obtained compassionate access to the PARP inhibitor rucaparib on the basis of the results from WGS showing a DDR pathway defect supported by the presence of mutation signature 3 (Fig. 3). $\mathrm{He}$ is alive 2 years following diagnosis of metastatic disease. WGS also showed loss of PTEN and CDKN2A. These offer further options for future therapeutic intervention with $\mathrm{mTOR}$ inhibitors and Aurora/VEGF inhibitors, respectively. 
This case illustrates that WGS can reveal acquired alterations in DDR genes, including homozygous deletions and deleterious SNVs, leading to therapeutic intervention.

\section{CASE 7 (Sarcoma)}

A 42-yr-old man presented with a soft tissue mass in the right axilla, and a biopsy of this showed a high-grade malignant tumor with a mostly epithelioid appearance (Fig. 1G) and extensive necrosis (Table 1). The initial diagnosis made by the referring center was that of a cancer of unknown primary, but the possibility of a dedifferentiated metastatic malignant melanoma or sarcoma was raised at the time. The patient commenced conventional chemotherapy. Following transfer of care to a specialist orthopedic center, histology review noted focal spindle cell areas and suggested a mesenchymal tumor origin. The tumor was immunereactive for S100 (nerve sheath marker) and INI1, focally positive for desmin and myogenin, and in some areas around necrotic foci, HIF1-a-positive (seen in neurofibromatosis 1). The tumor cells did not express CD45 (hematological), Melan A or HMB45 (differentiated melanoma markers), CD117 (GIST, dermatofibroma, angiosarcoma, Ewing's sarcoma), or phosphor-MET. FISH for the SS18 fusion gene (synovial sarcoma) was negative. The overall histopathological findings were most consistent with a malignant peripheral nerve sheath tumor (MPNST), showing rhabdomyosarcomatous differentiation (Triton tumor) as shown by desmin and myogenin immunopositivity. The absence of expression of H3K27me3 was also supportive of a histological diagnosis of MPNST (Lee et al. 2014; Prieto-Granada et al. 2016). An epithelioid MPNST was considered but thought to be unlikely because of INI1 IHC positivity. Furthermore, no CNA or $\mathrm{cnLOH}$ regions involving SMARCB1 were identified for this patient and no other inactivating mutations.

Shortly after initial presentation the patient developed metastatic disease in the left thigh. A biopsy showed similar histological findings and was subjected to WGS. TGS and WGS revealed a tier 1 mutation in NRAS (c.181C>A, p.Gln61 Lys), which indicates lack of response to anti-EGFR antibody therapy or BRAF inhibition and points to MEK-inhibitor therapy. Similar to Case 5, WGS revealed a high number of SNVs/indels consistent with a hypermutator genotype (Supplemental Fig. S1); therefore, SNV analysis presented is limited to Tier 1 findings only.

No translocation events typical of sarcoma were identified. However, WGS showed a complex karyotype including an acquired homozygous CN loss of CDKN2A (Aurora/VEGF inhibitors), loss of PTEN (mTOR inhibitors), and a somatically acquired loss of NF1, again indicating potential response to MEK inhibition. CDKN2A loss is a common event in cancer, and there is preclinical evidence for efficacy of CDK4/6 inhibitors in tumors with CDKN2A loss (Gao et al. 2015; Elvin et al. 2017). Interestingly, in a phase 1 trial of abemaciclib, a selective CDK4 and 6 inhibitor, a patient with metastatic melanoma achieved a PR carrying similar molecular alterations (NRAS mutation and copy-number loss at the INK4 locus) to Case 7 (Patnaik et al. 2016).

Surprisingly, the mutation signature strongly implied UV-light exposure (Fig. 3) as the underlying mutagenic mechanism, raising the possibility that the original suspected diagnosis of a dedifferentiated malignant melanoma was correct.

WGS of the germline of this patient revealed no mutation in NF1. Genes related to PRC2 components were also investigated. For SUZ12, Case 7 showed an acquired CN loss (Chr $17: 25,248,166-30,645,676)$ and for both $E Z H 1$ and EZH2, acquired subclonal CN losses were observed (Chr 7:98,693,981-159,138,663 and Chr 17:30,645,677-81,195,210, respectively). No CNAs or cnLOH events involving EED were identified. This made MPNST unlikely and highlights that the absence of H3K27me3 expression is not specific for this tumor type.

Shortly after submission of the sample for WGS, the patient developed widespread metastases and died. This case illustrates that even with extensive profiling, it is not always possible to provide a definite diagnosis. 


\section{CASE 8 (Soft Tissue Tumor)}

A 7-yr-old boy presented with neck pain due to a soft tissue mass causing subluxation at the C4/C5 vertebral level. Histology of the mass (Fig. $1 \mathrm{H}$ ) showed a cellular spindle cell lesion with focal nuclear atypia (Table 1). The tumor cells were immune-reactive for smooth muscle actin, but other soft tissue markers were negative. The proliferation index by $\mathrm{Ki} 67$ was $5 \%$, indicative of a low-grade lesion. FISH showed no evidence of common translocation events including SS18, EWSR1, and MDM2, and there was no amplification by real-time PCR for the sarcoma-associated fusion genes ETV6-NTRK3 and SS18-SSX1/2/ 4. Taken together, these findings were not sufficient for a definitive diagnosis. The differential diagnosis included infantile myofibroma, myofibrosarcoma, and a low-grade spindle cell sarcoma. At the time of sequencing, histology and initial results of molecular genetic tests, taken together with imaging and clinical context, were consistent with a low-grade sarcoma, not otherwise specified (NOS). WGS analysis did not reveal any sarcoma-associated translocations. There were no clearly pathogenic SNVs, and the mutational burden of the tumor was low (Supplemental Fig. 1). There was an acquired homozygous loss of CDKN2A and heterozygous acquired losses of PTEN, TSC1, and BRCA2 (Table 2). The Cancer Genomics MDT recommended mTOR inhibition with temsirolimus, PARP inhibition, or aurora/VEGF inhibitors as potential treatment options as there was no standard of care for this patient.

The patient was subsequently offered conventional empirical chemotherapy at the local center (doxorubicin, ifosfamide, etoposide) followed by surgical resection when imaging postchemotherapy showed marked tumor progression despite concerns regarding positive resection margins and associated morbidity and risks. This case highlights the reluctance to use information from WGS for clinical decision-making even in a palliative setting and in situations where there is no standard of care.

\section{WGS versus In Silico WES: Clinical Implications}

In summary, WGS led to identification of clinically actionable SNVs and CNAs for each case. Although exome sequencing can theoretically identify many of these changes, there are limitations to this approach. To explore whether the same results could have been obtained from WES, we applied an in silico filter to our WGS data using the SureSelect target regions and compared results obtained by the two different methods.

All clinically actionable SNVs detected by WGS in the eight patients were also detected when applying the in silico SureSelect filter on our data. However, for seven of the genes with actionable mutations in our cohort, 14 exons were not covered (Supplemental Table S6). Moreover, the SureSelect panel did not include 152 genes listed in the COSMIC Cancer Driver Gene List (Supplemental Table S7), and a further 2038 exons from remaining COSMIC genes are also not included in the panel (Supplemental Table S8). Furthermore, it is now well established that WES results will depend on the efficacy of capture and may miss up to $20 \%$ of targets. Unfortunately, it is not possible to predict which exonic regions these might be and therefore we could not simulate this in our analysis (Bamshad et al. 2011; Wang et al. 2017). For WGS of each cancer case, the average coverage across the entire genome is shown in Supplemental Table S9 and the percentage of COSMIC genes covered at $\times 75$, averaged over the eight cancer cases in Supplemental Table S10.

For CNA and cnLOH events, we did not identify any differences that would affect the clinically actionable findings for the patients presented. However, we did identify events affecting noncoding regions that demonstrate the potential advantages of WGS over WES. These included (a) intergenic and intronic copy-number losses, (b) intergenic and intronic breakpoints, and (c) altered levels of allelic imbalance that would have been missed by WES (Supplemental Fig. S3). 
For mutation analysis, we compared trinucleotide counts in our data to signatures from the COSMIC database (Supplemental Tables 11, 12 for WGS and WES, respectively). These signatures are based on whole-genome studies and are applicable to biological processes that affect the whole genome such as UV damage and smoking. Thus, the whole-genome data are more reflective of the true mutation signatures because we have more mutations and, therefore, more data to consider. We performed the signature analysis on regions defined by the SureSelect panel covering the whole exome and found that unless the samples contained an unusually large number of mutations (Cases 5 and 7) the signatures are not consistent with the WGS (Supplemental Fig. S4). We found that Case 5 is the only case with identical signatures in WGS and WES, though Cases 2 and 7 are similar.

\section{DISCUSSION}

To our knowledge, this is the first study to evaluate the potential clinical utility of WGS in management of a consecutive series of patients with advanced cancer of varying tissue origin. Strikingly, for the first eight patients recruited and described here, WGS led to the identification of clinically actionable changes in all eight cases. WGS results helped to clarify an uncertain histopathological diagnosis in one case (Case 5), raised the possibility of an alternative diagnosis in a second case (Case 7), informed or supported prognosis in two cases (Cases 2 and 5), directly informed treatment changes in three patients (Cases 2, 5, and 6), leading to the joint clinicians' and patients' decision to de-escalate therapy in one case (Case 2), and indicated potential treatment options in all eight cases. Overall 26 different tier 1 clinically actionable somatic findings were identified from WGS compared with six SNVs/indels using the routine TGS approach. These provide exemplars of all of the five different analysis approaches described in the Introduction.

In four patients (Cases 1, 3, 4, and 6) WGS revealed a likely biallelic DDR mutation signature that would have been missed by conventional targeted cancer panel approaches, as it was defined by integration of SNVs, indels, and copy-number losses and analysis of global mutation signatures. These were in very different tumor types (prostate, male breast, and colorectal), yet all would be amenable to pharmacological intervention. Indeed, one patient (Case 6) obtained compassionate access to a PARP inhibitor and remains in remission at $24 \mathrm{mo}$.

Mutation burden is an important indicator of prognosis and indicates patients suitable for treatment with checkpoint inhibitors. In our study, a patient with endometrial cancer (Case 5) showed ultramutation because of a somatic POLE exonuclease domain mutation, findings associated with excellent prognosis of endometrial cancers, and the patient therefore opted to decline chemotherapy, thereby avoiding the associated toxicity (van Gool et al. 2016). Treatment with checkpoint inhibitors remains an option for this patient should she show clinical signs of relapse.

In contrast to conventional TGS, WGS provides information on both somatic and germline variants. This is important, as the same genes may underpin acquired or inherited cancers. For example, we identified acquired copy-number changes in BRCA1/2 that enabled synthetic lethal drugs to be used. Similarly, mutations in POLE were originally identified in inherited colorectal cancers but have since been recognized as somatic changes in both colorectal and endometrial cancers. Finally, Case 4 carried a deleterious germline variant in $R A D 51 B$ and acquired loss of the other allele in the tumor. This information might be important for informing families of the genetic risk of cancer (Briggs and Tomlinson 2013) and also to pinpoint a homozygous impairment of the DDR pathway.

Several cancers are known to be associated with viruses (Martin and Gutkind 2008). In our series, Case 2 (oropharyngeal cancer) had an HPV etiology indicated by p16 immunohistochemistry (a surrogate marker for HPV infection), which indicates a better prognosis than 
HPV-negative or smoking-related oral tumors (Duncan et al. 2013). IHC testing, however, has limitations, including a significant false-positive rate, and does not indicate viral subtype. WGS provided direct confirmation of the virus presence, as well as the subtype (Mahajan 2016). This is important as clinical trials relating to de-escalation of therapy in patients with good prognosis are underway. In addition to confirming the HPV status, WGS also informed the management of side effects leading to de-escalation and the choice of alternative therapy by confirming lack of DDR mutations and absence of EGFR mutations, which would have conferred resistance to cetuximab.

We did not find any clinically actionable mutations in noncoding regions or actionable translocations. Evidence of the clinical actionability of these types of events in solid tumors remains limited. For noncoding regions, mutations in the promoter of TERT2 gene are welldescribed (Huang et al. 2013), but these did not occur in our cohort. Clinically actionable or recurrent translocations have been described in lung and prostate cancer but were absent in our patients. Interestingly, sarcomas are characterized by frequent translocation events. However, the patient in our cohort who was referred with a possible sarcoma diagnosis but was found to have a UV light signature also did not carry any sarcoma-associated translocations, further strengthening the possibility that the primary tumor was not a sarcoma.

The turnaround time of WGS for cancer patients is critical. Two of the patients (Cases 1 and 7) died before WGS could be completed. Referral of patients for WGS should be encouraged at earlier stages in the disease course. Our fastest turnaround time for the whole process (including pathological assessment, release of tissue blocks, sequencing, and analysis stages) was 3 wk.

In the United Kingdom's National Health Service (NHS), we were limited by the availability of established funded therapies. Two treatment regimens emerge from this study as being of particular importance: PARP inhibitors for patients with defects in the DDR pathway and PDL1 checkpoint inhibitors for cancers showing hypermutation. These were made available through clinical trials or compassionate use. Clearly, this limited pilot study does not allow any conclusions regarding improvement in clinical outcome of patients undergoing the precision medicine approach presented herein. The challenges of testing physicians' choice versus molecularly directed therapy in a randomized clinical trial setting highlighted by the SHIVA trial (Le Tourneau et al. 2015). Since then, major efforts using extensive targeted sequencing efforts systematically on thousands of patients with advanced cancer have demonstrated clinical utility in $35 \%$ of patients. Other similar studies have been initiated (Zehir et al. 2017).

Nonetheless, the results of this initial pilot study demonstrate that WGS can have an impact on informing diagnosis, prognosis, and potential treatment choice, including access to clinical trials, and justifies the systematic evaluation of the clinical utility of WGS in the management of patients with cancer in larger cohorts of patients.

\section{METHODS}

\section{Patients and Ethics}

The first eight patients referred consecutively to the study are described (i.e., there was no preselection of cases). Patients were consented for analysis of tumor and constitutional DNA and feedback of somatic genetic testing results by a clinician. Feedback of clinically actionable germline variants was optional. Details of ethical approval are highlighted below.

\section{Sample Preparation and DNA Extraction}

Tumor Tissue Handling

All patients underwent biopsy of primary and/or metastatic cancer to obtain fresh tissue for sequencing. Fresh tissue samples were collected either by the clinician at the time of biopsy 
or from the resection specimen by the pathologist at dissection. Samples were snap-frozen in liquid nitrogen and an H\&E frozen histology section was taken to confirm tissue content. Only samples with microscopically estimated tumor cell content of $>40 \%$ were used for sequencing. Further formalin-fixed, paraffin-embedded (FFPE) tissue samples were collected for routine diagnostic histopathology, applying standard processing protocols such as H\&E staining and IHC as appropriate. Frozen tissue was thawed rapidly for nucleic acid extraction. All samples underwent targeted sequencing using the 46 Gene Cancer Panel (as described in Hamblin et al. 2017) and WGS (methods described below and in Supplemental Information).

\section{DNA Extraction}

Constitutional DNA was isolated from $1.5 \mathrm{ml}$ peripheral blood using the QIASymphony DSP DNA Midi kit (QIAGEN), according to the manufacturer's protocol. Tumor DNA was extracted from fresh frozen tissue using the All Prep Mini DNA Extraction kit (QIAGEN), as described in the manufacturer's protocol.

\section{Whole-Genome Sequencing}

Libraries of 350-bp fragments were generated from $1 \mu$ g sheared genomic DNA using the TruSeq PCR-Free library preparation kit (Illumina). Of note, $2 \times 126$ paired-end sequencing was performed using the HiSeq2500 HTv4 (Illumina). WGS was performed at a planned coverage of $30 \times$ for the constitutional DNA and of $75 \times$ for the tumor. The average coverage data across the entire genome per case, expressed as average number of reads, is shown in Supplemental Table 9 and the percentage of the genes covered at 75×, averaged over the eight tumor samples tested, in Supplemental Table 10.

\section{Data Analysis}

For a detailed description of alignment to the human reference genome, SNV, and structural variant calling, calculations of absolute exonic and intronic mutation burden, identification of previously described mutation signatures (Alexandrov et al. 2013a), the calculations of COSMIC signatures (Rosenthal et al. 2016), annotations of coding and noncoding variants, and detection of viral sequences, please refer to the Supplemental Materials and Methods.

Briefly, analysis was performed using a bespoke, locked-down, and version-controlled bioinformatics pipeline according to the required specification for clinically accredited laboratories.

Paired-end alignment of sequencing data against the reference genome hg19 (GRCh 37) was performed using the Whole-Genome Sequencing Application v2.0, based on Isaac Alignment Tool, within BaseSpace (Illumina). Somatic single nucleotide (SNV) and insertion/deletion (InDel) variant calling analysis was performed using the Tumour-Normal Application v1.0, based on Strelka, within BaseSpace. Calls were annotated using VariantStudio v2 (Illumina), a software using variant effect predictor (VEP) v2.8, COSMIC v77 and 1000 Genomes (v3). In a second approach, data were analyzed using QIAGEN's Ingenuity Variant Analysis software (QIAGEN Redwood City).

For copy-number and zygosity detection and analyses, $\log _{2} R$ values were generated from paired and unpaired tumor and germline data and these, together with B-allele frequency (BAF) outputs, were analyzed and events flagged and visualized using Nexus Discovery Edition 7.5 (BioDiscovery, Inc., El Segundo, CA).

Translocation events were investigated using BreakDancer (v1.4.5). Analysis was limited to a set of cancer-specific genes, as previously defined (Huret et al. 2013). 
Presence of HPV was determined by alignment of tumor sample reads using bwa (Li and Durbin 2009). HPV was confirmed and the HPV-35 subtype further classified by HPVDetector (Chandrani et al. 2015).

\section{In Silico Whole-Exome Analysis}

To explore whether we would have obtained similar or identical results from WES to those obtained by WGS, we applied an in silico filter using the Agilent SureSelect exome panel. SNVs, indels, and CNVs were then analyzed as in the WGS analyses described above and in the main text.

\section{Interpretation of Pathogenicity and Clinical Impact}

All SNVs, indels, CNAs, and copy-neutral regions of homozygosity (cnLOHs) were classified with respect to their pathogenicity and clinical actionability (Futreal et al. 2004) (see Supplemental Information), information relating to germline and somatic changes at the respective locus was integrated. Analysis of germline changes was limited to a predefined in silico targeted panel of genes (Supplemental Table S3).

Specifically for defects in the DDR pathway, only inferred homozygous mutations were classified as clinically actionable. Allelic imbalance was not clinically actionable. For cases with hypermutated genotype (Cases 5 and 7) only clearly actionable mutations were included. A number of different sources, including COSMIC Cancer Genes Census (v77), "My Cancer Genome" (https://www.mycancergenome.org), and ClinicalTrials.gov (http:// clinicaltrials.gov) were used to determine whether genetic alterations were clinically relevant. Using this information, mutations were classified as tier 1, tier 2, or tier 3 (Li et al. 2017). Tier 1 variants were defined by strong prognostic or diagnostic relevance and/or clinically actionability based on the availability of either an FDA/EMA approved therapy or access to clinical trials relevant to the indication. Tier 2 variants were defined as those that might contribute to confirming the pathological diagnosis or have established biological relevance and/or those for which a clinical trial or approved therapy in a different tumor type was available. Tier 3 variants are those of unknown significance.

All variants showing annotations of potential clinical significance (tier 1 and 2 variants; see Table 2) were inspected manually using the integrative genomics viewer (IGV) (Robinson et al. 2011).

All results were fed back to clinicians in an integrated molecular and histopathological report overseen by the Genomics Tumour Board consisting of clinicians, senior clinical scientists, bioinformaticians, and histopathologists (Wagle et al. 2012; Dienstmann et al. 2014).

\section{ADDITIONAL INFORMATION}

\section{Data Deposition and Access}

The tier 1 and tier 2 variants identified in this study have been submitted to ClinVar (https:// www.ncbi.nlm.nih.gov/clinvar/) and can be found under accession numbers SCV000493830 PTEN Chr 10:85557432-105804295 CN Loss; SCV000493831 BRCA2 Chr 13:32178877$33860144 \mathrm{CN}$ Loss (Homozygous); and SCV000493829 TP53 Chr 17:7573975 NM_000546.5: c1044_1051 delGGAACTCA.

\section{Ethics Statement}

Written informed consent was obtained in line with the Declaration of Helsinki and local research ethics committees following the procedures outlined by the Oxford Radcliffe Biobank (South Central-Berkshire B Research Ethics Committee [REC no: 14/SC/1165]). 
Competing Interest Statement

The authors have declared no competing interest.

\section{Referees}

Edwin Cuppen

Anonymous

Received August 30, 2017; accepted in revised form February 9, 2018.

\section{Author Contributions}

A.S. and J.C.T. designed the study, interpreted results wrote the first draft, and edited the manuscript; H.D., S.J.L.K., T.M., P.A., D.V., K.R., E.M.K., M.M.P., and N.P. performed data analyses and contributed to Introduction, Methods, Results, and Discussion sections, R.C., A.H., A.P., M.P., K.A.S., Z.O., N.A., B.H., A.M.F., A.A., S.W., A.H., I.T., and D.C. contributed clinical and pathology data and assisted with the clinical interpretation of results.

\section{Funding}

This publication presents independent research commissioned by the Health Innovation Challenge Fund (R6-388/WT 100127), a parallel funding partnership between the Wellcome Trust and the Department of Health. The authors also acknowledge a funding contribution from the Wellcome Trust Core award Grant Number 203141/Z/16/Z. This work was also funded and supported by the National Institute for Health Research (NIHR) Oxford Biomedical Research Centre (BRC). The views expressed are those of the authors and not necessarily those of the Wellcome Trust, Department of Health, National Health Service (NHS), or the NIHR.

\section{REFERENCES}

Alexandrov LB, Nik-Zainal S, Wedge DC, Aparicio SA, Behjati S, Biankin AV, Bignell GR, Bolli N, Borg A Borresen-Dale AL, et al. 2013a. Signatures of mutational processes in human cancer. Nature 500: 415-421.

Alexandrov LB, Nik-Zainal S, Wedge DC, Campbell PJ, Stratton MR. 2013b. Deciphering signatures of mutational processes operative in human cancer. Cell Rep 3: 246-259.

Amado RG, Wolf M, Peeters M, Van Cutsem E, Siena S, Freeman DJ, Juan T, Sikorski R, Suggs S, Radinsky R, et al. 2008. Wild-type KRAS is required for panitumumab efficacy in patients with metastatic colorectal cancer. J Clin Oncol 26: 1626-1634.

Bamshad MJ, Ng SB, Bigham AW, Tabor HK, Emond MJ, Nickerson DA, Shendure J. 2011. Exome sequencing as a tool for Mendelian disease gene discovery. Nat Rev Genet 12: 745-755.

Banerji S, Cibulskis K, Rangel-Escareno C, Brown KK, Carter SL, Frederick AM, Lawrence MS, Sivachenko AY, Sougnez C, Zou L, et al. 2012. Sequence analysis of mutations and translocations across breast cancer subtypes. Nature 486: 405-409.

Bansal N, Yendluri V, Wenham RM. 2009. The molecular biology of endometrial cancers and the implications for pathogenesis, classification, and targeted therapies. Cancer Control 16: 8-13.

Bitler BG, Aird KM, Garipov A, Li H, Amatangelo M, Kossenkov AV, Schultz DC, Liu Q, Shih leM, ConejoGarcia JR, et al. 2015a. Synthetic lethality by targeting EZH2 methyltransferase activity in ARID1A-mutated cancers. Nat Med 21: 231-238.

Bitler BG, Fatkhutdinov N, Zhang R. 2015b. Potential therapeutic targets in ARID1A-mutated cancers. Expert Opin Ther Targets 19: 1419-1422.

Briggs S, Tomlinson I. 2013. Germline and somatic polymerase $\varepsilon$ and $\delta$ mutations define a new class of hypermutated colorectal and endometrial cancers. J Pathol 230: 148-153.

Chabanon RM, Pedrero M, Lefebvre C, Marabelle A, Soria JC, Postel-Vinay S. 2016. Mutational landscape and sensitivity to immune checkpoint blockers. Clin Cancer Res 22: 4309-4321.

Chandrani P, Upadhyay P, lyer P, Tanna M, Shetty M, Raghuram GV, Oak N, Singh A, Chaubal R, Ramteke M, et al. 2015. Integrated genomics approach to identify biologically relevant alterations in fewer samples. BMC Genomics 16: 936.

Church DN, Stelloo E, Nout RA, Valtcheva N, Depreeuw J, ter Haar N, Noske A, Amant F, Tomlinson IP, Wild PJ, et al. 2014. Prognostic significance of POLE proofreading mutations in endometrial cancer. $J$ Natl Cancer Inst 107: 402.

Curtis C, Shah SP, Chin SF, Turashvili G, Rueda OM, Dunning MJ, Speed D, Lynch AG, Samarajiwa S, Yuan Y, et al. 2012. The genomic and transcriptomic architecture of 2,000 breast tumours reveals novel subgroups. Nature 486: 346-352.

Dalla-Favera R, Bregni M, Erikson J, Patterson D, Gallo RC, Croce CM. 1982. Human c-myc onc gene is located on the region of Chromosome 8 that is translocated in Burkitt lymphoma cells. Proc Natl Acad Sci 79: $7824-7827$ 
Dienstmann R, Dong F, Borger D, Dias-Santagata D, Ellisen LW, Le LP, lafrate AJ. 2014. Standardized decision support in next generation sequencing reports of somatic cancer variants. Mol Oncol 8: 859-873.

Dietlein F, Thelen L, Jokic M, Jachimowicz RD, Ivan L, Knittel G, Leeser U, van Oers J, Edelmann W, Heukamp LC, et al. 2014. A functional cancer genomics screen identifies a druggable synthetic lethal interaction between MSH3 and PRKDC. Cancer Discov 4: 592-605.

Dreazen O, Klisak I, Jones G, Ho WG, Sparkes RS, Gale RP. 1987. Multiple molecular abnormalities in Ph1 chromosome positive acute lymphoblastic leukaemia. Br J Haematol 67: 319-324.

Dreger P, Schnaiter A, Zenz T, Boöttcher S, Rossi M, Paschka P, Buühler A, Dietrich S, Busch R, Ritgen M, et al. 2013. TP53, SF3B1, and NOTCH1 mutations and outcome of allotransplantation for chronic lymphocytic leukemia: six-year follow-up of the GCLLSG CLL3X trial. Blood 121: 3284-3288.

Duncan LD, Winkler M, Carlson ER, Heidel RE, Kang E, Webb D. 2013. p16 immunohistochemistry can be used to detect human papillomavirus in oral cavity squamous cell carcinoma. J Oral Maxillofac Surg 71: 1367-1375.

Ellis MJ, Ding L, Shen D, Luo J, Suman VJ, Wallis JW, Van Tine BA, Hoog J, Goiffon RJ, Goldstein TC, et al. 2012. Whole-genome analysis informs breast cancer response to aromatase inhibition. Nature 486: 353-360.

Elvin JA, Gay LM, Ort R, Shuluk J, Long J, Shelley L, Lee R, Chalmers ZR, Frampton GM, Ali SM, et al. 2017. Clinical benefit in response to Palbociclib treatment in refractory uterine leiomyosarcomas with a common CDKN2A alteration. Oncologist 22: 416-421.

Fong PC, Boss DS, Yap TA, Tutt A, Wu P, Mergui-Roelvink M, Mortimer P, Swaisland H, Lau A, O'Connor MJ, et al. 2009. Inhibition of poly(ADP-ribose) polymerase in tumors from BRCA mutation carriers. N Engl J Med 361: 123-134.

Fong PC, Yap TA, Boss DS, Carden CP, Mergui-Roelvink M, Gourley C, De Greve J, Lubinski J, Shanley S, Messiou C, et al. 2010. Poly(ADP)-ribose polymerase inhibition: frequent durable responses in BRCA carrier ovarian cancer correlating with platinum-free interval. J Clin Oncol 28: 2512-2519.

Futreal PA, Coin L, Marshall M, Down T, Hubbard T, Wooster R, Rahman N, Stratton MR. 2004. A census of human cancer genes. Nat Rev Cancer 4: 177-183.

Gao J, Adams RP, Swain SM. 2015. Does CDKN2A loss predict palbociclib benefit? Curr Oncol 22: e498-e501.

Hamblin A, Wordsworth S, Fermont JM, Page S, Kaur K, Camps C, Kaisaki P, Gupta A, Talbot D, Middleton $\mathrm{M}$, et al. 2017. Clinical applicability and cost of a 46-gene panel for genomic analysis of solid tumours: retrospective validation and prospective audit in the UK National Health Service. PLoS Med 14: e1002230

Heemskerk B, Kvistborg P, Schumacher TN. 2013. The cancer antigenome. EMBO J 32: 194-203.

Huang FW, Hodis E, Xu MJ, Kryukov GV, Chin L, Garraway LA. 2013. Highly recurrent TERT promoter mutations in human melanoma. Science 339: 957-959.

Huret JL, Ahmad M, Arsaban M, Bernheim A, Cigna J, Desangles F, Guignard JC, Jacquemot-Perbal MC, Labarussias M, Leberre V, et al. 2013. Atlas of Genetics and Cytogenetics in Oncology and Haematology in 2013. Nucleic Acids Res 41(Database issue): D920-D924.

Hussein YR, Weigelt B, Levine DA, Schoolmeester JK, Dao LN, Balzer BL, Liles G, Karlan B, Köbel M, Lee CH, et al. 2015. Clinicopathological analysis of endometrial carcinomas harboring somatic POLE exonuclease domain mutations. Mod Pathol 28: 505-514.

lida M, Takayama E, Naganawa K, Mitsudo K, Adachi M, Baba J, Fujimoto-Muto M, Motohashi M, MizunoKamiya M, Kawaki H, et al. 2014. Increase of peripheral blood CD57 ${ }^{+}$T-cells in patients with oral squamous cell carcinoma. Anticancer Res 34: 5729-5734.

Kaspar HG, Crum CP. 2015. The utility of immunohistochemistry in the differential diagnosis of gynecologic disorders. Arch Pathol Lab Med 139: 39-54.

Khurana E, Fu Y, Chakravarty D, Demichelis F, Rubin MA, Gerstein M. 2016. Role of non-coding sequence variants in cancer. Nat Rev Genet 17: 93-108.

Kristeleit RS, Miller RE, Kohn EC. 2016. Gynecologic cancers: emerging novel strategies for targeting DNA repair deficiency. Am Soc Clin Oncol Educ Book 35: e259-e268.

Langendijk JA, Psyrri A. 2010. The prognostic significance of p16 overexpression in oropharyngeal squamous cell carcinoma: implications for treatment strategies and future clinical studies. Ann Oncol 21: 1931-1934.

Larson RA, Kondo K, Vardiman JW, Butler AE, Golomb HM, Rowley JD. 1984. Evidence for a 15;17 translocation in every patient with acute promyelocytic leukemia. Am J Med 76: 827-841.

Laskin J, Jones S, Aparicio S, Chia S, Ch'ng C, Deyell R, Eirew P, Fok A, Gelmon K, Ho C, et al. 2015. Lessons learned from the application of whole-genome analysis to the treatment of patients with advanced cancers. Cold Spring Harb Mol Case Stud 1: a000570.

Le Tourneau C, Belin L, Paoletti X, Bieche I, Kamal M. 2015. Precision medicine: lessons learned from the SHIVA trial-author's reply. Lancet Oncol 16: e581-e582. 
Ledermann J, Harter P, Gourley C, Friedlander M, Vergote I, Rustin G, Scott C, Meier W, Shapira-Frommer R, Safra T, et al. 2012. Olaparib maintenance therapy in platinum-sensitive relapsed ovarian cancer. N Engl J Med 366: 1382-1392.

Lee W, Teckie S, Wiesner T, Ran L, Prieto Granada CN, Lin M, Zhu S, Cao Z, Liang Y, Sboner A, et al. 2014. PRC2 is recurrently inactivated through EED or SUZ12 loss in malignant peripheral nerve sheath tumors. Nat Genet 46: 1227-1232.

Li H, Durbin R. 2009. Fast and accurate short read alignment with Burrows-Wheeler transform. Bioinformatics 25: 1754-1760.

Li MM, Datto M, Duncavage EJ, Kulkarni S, Lindeman NI, Roy S, Tsimberidou AM, VnencakJones CL, Wolff DJ, Younes A, et al. 2017. Standards and guidelines for the interpretation and reporting of sequence variants in cancer: a joint consensus recommendation of the Association for Molecular Pathology, American Society of Clinical Oncology, and College of American Pathologists. J Mol Diagn 19: 4-23.

Lin K, Lane B, Carter A, Johnson GG, Onwuazor O, Oates M, Zenz T, Stilgenbauer S, Atherton M, Douglas A et al. 2013. The gene expression signature associated with TP53 mutation/deletion in chronic lymphocytic leukaemia is dominated by the under-expression of TP53 and other genes on Chromosome 17p. Br J Haematol 160: 53-62.

Lipianskaya J, Cohen A, Chen CJ, Hsia E, Squires J, Li Z, Zhang Y, Li W, Chen X, Xu H, et al. 2014. Androgendeprivation therapy-induced aggressive prostate cancer with neuroendocrine differentiation. Asian $J$ Androl 16: 541-544.

Maccaroni E, Bracci R, Giampieri R, Bianchi F, Belvederesi L, Brugiati C, Pagliaretta S, Del Prete M, Scartozzi M, Cascinu S. 2015. Prognostic impact of mismatch repair genes germline defects in colorectal cancer patients: are all mutations equal? Oncotarget 6: 38737-38748.

Mahajan A. 2016. Practical issues in the application of p16 immunohistochemistry in diagnostic pathology. Hum Pathol 51: 64-74.

Manolov G, Manolova Y. 1972. Marker band in one Chromosome 14 from Burkitt lymphomas. Nature 237: 33-34.

Martin D, Gutkind JS. 2008. Human tumor-associated viruses and new insights into the molecular mechanisms of cancer. Oncogene 27(Suppl 2): S31-S42.

Mateo J, Carreira S, Sandhu S, Miranda S, Mossop H, Perez-Lopez R, Nava Rodrigues D, Robinson D, Omlin A, Tunariu N, et al. 2015. DNA-repair defects and olaparib in metastatic prostate cancer. N Engl J Med 373: 1697-1708.

McGranahan N, Furness AJ, Rosenthal R, Ramskov S, Lyngaa R, Saini SK, Jamal-Hanjani M, Wilson GA, Birkbak NJ, Hiley CT, et al. 2016. Clonal neoantigens elicit T cell immunoreactivity and sensitivity to immune checkpoint blockade. Science 351: 1463-1469.

Miyoshi Y, Uemura H, Kitami K, Satomi Y, Kubota Y, Hosaka M. 2001. Neuroendocrine differentiated small cell carcinoma presenting as recurrent prostate cancer after androgen deprivation therapy. BJU Int 88: 982-983.

Nadal R, Schweizer M, Kryvenko ON, Epstein JI, Eisenberger MA. 2014. Small cell carcinoma of the prostate. Nat Rev Urol 11: 213-219.

Nik-Zainal S, Wedge DC, Alexandrov LB, Petljak M, Butler AP, Bolli N, Davies HR, Knappskog S, Martin S, Papaemmanuil $E$, et al. 2014. Association of a germline copy number polymorphism of APOBEC 3 A and $A P O B E C 3 B$ with burden of putative APOBEC-dependent mutations in breast cancer. Nature Genetics 46: 487-491.

Nik-Zainal S, Davies H, Staaf J, Ramakrishna M, Glodzik D, Zou X, Martincorena I, Alexandrov LB, Martin S, Wedge DC, et al. 2016. Landscape of somatic mutations in 560 breast cancer whole-genome sequences. Nature 534: 47-54.

Parker BC, Zhang W. 2013. Fusion genes in solid tumors: an emerging target for cancer diagnosis and treatment. Chin J Cancer 32: 594-603.

Parsons DW, Jones S, Zhang X, Lin JC, Leary RJ, Angenendt P, Mankoo P, Carter H, Siu IM, Gallia GL, et al. 2008. An integrated genomic analysis of human glioblastoma multiforme. Science 321: 1807-1812.

Patnaik A, Rosen LS, Tolaney SM, Tolcher AW, Goldman JW, Gandhi L, Papadopoulos KP, Beeram M, Rasco DW, Hilton JF, et al. 2016. Efficacy and safety of abemaciclib, an inhibitor of CDK4 and CDK6, for patients with breast cancer, non-small cell lung cancer, and other solid tumors. Cancer Discov 6: 740-753.

Pleasance ED, Cheetham RK, Stephens PJ, McBride DJ, Humphray SJ, Greenman CD, Varela I, Lin ML, Ordonez GR, Bignell GR, et al. 2010a. A comprehensive catalogue of somatic mutations from a human cancer genome. Nature 463: 191-196.

Pleasance ED, Stephens PJ, O'Meara S, McBride DJ, Meynert A, Jones D, Lin ML, Beare D, Lau KW, Greenman C, et al. 2010b. A small-cell lung cancer genome with complex signatures of tobacco exposure. Nature 463: 184-190. 
Prieto-Granada CN, Wiesner T, Messina JL, Jungbluth AA, Chi P, Antonescu CR. 2016. Loss of H3K27me3 expression is a highly sensitive marker for sporadic and radiation-induced MPNST. Am J Surg Pathol 40: 479-489.

Prindle MJ, Fox EJ, Loeb LA. 2010. The mutator phenotype in cancer: molecular mechanisms and targeting strategies. Curr Drug Targets 11: 1296-1303.

Pritchard CC, Mateo J, Walsh MF, De Sarkar N, Abida W, Beltran H, Garofalo A, Gulati R, Carreira S, Eeles R, et al. 2016. Inherited DNA-repair gene mutations in men with metastatic prostate cancer. N Engl J Med 375: 443-453.

Puente XS, Beaà S, Valdeés-Mas R, Villamor N, Gutieérrez-Abril J, Martiín-Subero Jl, Munar M, RubioPeérez C, Jares $P$, Aymerich $M$, et al. 2015. Non-coding recurrent mutations in chronic lymphocytic leukaemia. Nature 526: 519-524.

Riabinska A, Daheim M, Herter-Sprie GS, Winkler J, Fritz C, Hallek M, Thomas RK, Kreuzer KA, Frenzel LP, Monfared $\mathrm{P}$, et al. 2013. Therapeutic targeting of a robust non-oncogene addiction to PRKDC in ATM-defective tumors. Sci Transl Med 5: 189ra78.

Robinson JT, Thorvaldsdoóttir H, Winckler W, Guttman M, Lander ES, Getz G, Mesirov JP. 2011. Integrative Genomics Viewer. Nat Biotechnol 29: 24-26.

Rosenthal R, McGranahan N, Herrero J, Taylor B, Swanton C. 2016. DeconstructSigs: delineating mutational processes in single tumors distinguishes DNA repair deficiencies and patterns of carcinoma evolution. Genome Biology 17: 31.

Rowley JD. 1973. Letter: a new consistent chromosomal abnormality in chronic myelogenous leukaemia identified by quinacrine fluorescence and Giemsa staining. Nature 243: 290-293.

Santin AD, Bellone S, Centritto F, Schlessinger J, Lifton R. 2015. Improved survival of patients with hypermutation in uterine serous carcinoma. Gynecol Oncol Rep 12: 3-4.

Santin AD, Bellone S, Buza N, Choi J, Schwartz PE, Schlessinger J, Lifton RP. 2016. Regression of chemotherapy-resistant polymerase $\varepsilon$ (POLE) ultra-mutated and MSH6 hyper-mutated endometrial tumors with Nivolumab. Clin Cancer Res 22: 5682-5687.

Seiwert TY, Zuo Z, Keck MK, Khattri A, Pedamallu CS, Stricker T, Brown C, Pugh TJ, Stojanov P, Cho J, et al. 2015. Integrative and comparative genomic analysis of HPV-positive and HPV-negative head and neck squamous cell carcinomas. Clin Cancer Res 21: 632-641.

SGO Clinical Practice Endometrial Cancer Working Group, Burke WM, Orr J, Leitao M, Salom E, Gehrig P, Olawaiye AB, Brewer M, Boruta D, Herzog TJ, et al. 2014a. Endometrial cancer: a review and current management strategies: part II. Gynecol Oncol 134: 393-402.

SGO Clinical Practice Endometrial Cancer Working Group, Burke WM, Orr J, Leitao M, Salom E, Gehrig P, Olawaiye AB, Brewer M, Boruta D, Villella J, et al. 2014b. Endometrial cancer: a review and current management strategies: part I. Gynecol Oncol 134: 385-392.

Shah SP, Roth A, Goya R, Oloumi A, Ha G, Zhao Y, Turashvili G, Ding J, Tse K, Haffari G, et al. 2012. The clonal and mutational evolution spectrum of primary triple-negative breast cancers. Nature 486: 395-399.

Shtivelman E, Lifshitz B, Gale RP, Canaani E. 1985. Fused transcript of abl and bcr genes in chronic myelogenous leukaemia. Nature 315: 550-554.

Smith KS, Yadav VK, Pei S, Pollyea DA, Jordan CT, De S. 2016. SomVarlUS: somatic variant identification from unpaired tissue samples. Bioinformatics 32: 808-813.

Stelloo E, Bosse T, Nout RA, MacKay HJ, Church DN, Nijman HW, Leary A, Edmondson RJ, Powell ME, Crosbie EJ, et al. 2015. Refining prognosis and identifying targetable pathways for high-risk endometrial cancer; a TransPORTEC initiative. Mod Pathol 6: 836-844.

Stephens PJ, Tarpey PS, Davies H, Van Loo P, Greenman C, Wedge DC, Nik-Zainal S, Martin S, Varela I, Bignell GR, et al. 2012. The landscape of cancer genes and mutational processes in breast cancer. Nature 486: 400-404.

Stover EH, Konstantinopoulos PA, Matulonis UA, Swisher EM. 2016. Biomarkers of response and resistance to DNA repair targeted therapies. Clin Cancer Res 23: 5651-5660.

Strickland KC, Howitt BE, Shukla SA, Rodig S, Ritterhouse LL, Liu JF, Garber JE, Chowdhury D, Wu CJ, D'Andrea AD, et al. 2016. Association and prognostic significance of BRCA1/2-mutation status with neoantigen load, number of tumor-infiltrating lymphocytes and expression of PD-1/PD-L1 in high grade serous ovarian cancer. Oncotarget 7: 13587-13598.

Tajima S, Koda K. 2015. A case of a CD56-expressing ectomesenchymal chondromyxoid tumor of the tongue: potential diagnostic usefulness of commonly available CD56 over CD57. Int J Clin Exp Pathol 8: 3328-3333.

Tan DS, Rothermundt C, Thomas K, Bancroft E, Eeles R, Shanley S, Ardern-Jones A, Norman A, Kaye SB, Gore ME. 2008. "BRCAness" syndrome in ovarian cancer: a case-control study describing the clinical features and outcome of patients with epithelial ovarian cancer associated with BRCA1 and BRCA2 mutations. J Clin Oncol 26: 5530-5536. 
Tashiro H, Isacson C, Levine R, Kurman RJ, Cho KR, Hedrick L. 1997. p53 gene mutations are common in uterine serous carcinoma and occur early in their pathogenesis. Am J Pathol 150: 177-185.

te Raa GD, Malcikova J, Pospisilova S, Trbusek M, Mraz M, Garff-Tavernier ML, Merle-Beéral H, Lin K, Pettitt AR, Merkel O, et al. 2013. Overview of available p53 function tests in relation to TP53 and ATM gene alterations and chemoresistance in chronic lymphocytic leukemia. Leuk Lymphoma 54: 1849-1853.

The Cancer Genome Atlas Network. 2012. Comprehensive molecular portraits of human breast tumours. Nature 490: 61-70.

Turner NC, Ro J, Andreé F, Loi S, Verma S, Iwata H, Harbeck N, Loibl S, Huang Bartlett C, Zhang K, et al. 2015 Palbociclib in hormone-receptor-positive advanced breast cancer. N Engl J Med 373: 209-219.

van Gool IC, Eggink FA, Freeman-Mills L, Stelloo E, Marchi E, de Bruyn M, Palles C, Nout RA, de Kroon CD, Osse EM, et al. 2015. POLE proofreading mutations elicit an antitumor immune response in endometria cancer. Clin Cancer Res 21: 3347-3355.

van Gool IC, Bosse T, Church DN. 2016. POLE proofreading mutation, immune response and prognosis in endometrial cancer. Oncoimmunology 5: e1072675.

van Gool IC, Ubachs JEH, Stelloo E, de Kroon CD, Goeman JJ, Smit VTHBM, Creutzberg CL, Bosse T. 2018. Blinded histopathological characterisation of POLE exonuclease domain-mutant endometrial cancers: sheep in wolf's clothing. Histopathology 72: 248-258.

Vinagre J, Almeida A, Poópulo H, Batista R, Lyra J, Pinto V, Coelho R, Celestino R, Prazeres H, Lima L, et al. 2013. Frequency of TERT promoter mutations in human cancers. Nat Commun 4: 2185.

Waddell N, Pajic M, Patch AM, Chang DK, Kassahn KS, Bailey P, Johns AL, Miller D, Nones K, Quek K, et al. 2015. Whole genomes redefine the mutational landscape of pancreatic cancer. Nature 518: 495-501.

Wagle N, Berger MF, Davis MJ, Blumenstiel B, Defelice M, Pochanard P, Ducar M, Van Hummelen P, Macconaill LE, Hahn WC, et al. 2012. High-throughput detection of actionable genomic alterations in clinical tumor samples by targeted, massively parallel sequencing. Cancer Discov 2: 82-93.

Wang Q, Shashikant CS, Jensen M, Altman NS, Girirajan S. 2017. Novel metrics to measure coverage in whole exome sequencing datasets reveal local and global non-uniformity. Sci Rep 7: 885.

Yemelyanova A, Vang R, Kshirsagar M, Lu D, Marks MA, Shih le M, Kurman RJ. 2011. Immunohistochemical staining patterns of p53 can serve as a surrogate marker for TP53 mutations in ovarian carcinoma: an immunohistochemical and nucleotide sequencing analysis. Mod Pathol 24: 1248-1253.

Zehir A, Benayed R, Shah RH, Syed A, Middha S, Kim HR, et al. 2017. Mutational landscape of metastatic cancer revealed from prospective clinical sequencing of 10,000 patients. Nat Med 6: 703-713.

Zenz T, Eichhorst B, Busch R, Denzel T, Haäbe S, Winkler D, Buühler A, Edelmann J, Bergmann M, Hopfinger G, et al. 2010. TP53 mutation and survival in chronic lymphocytic leukemia. J Clin Oncol 28: 4473-4479. 


\section{COLD SPRING HARBOR Molecular Case Studies}

\section{Clinically actionable mutation profiles in patients with cancer identified by whole-genome sequencing}

Anna Schuh, Helene Dreau, Samantha J.L. Knight, et al.

Cold Spring Harb Mol Case Stud 2018, 4: a002279

Access the most recent version at doi: $10.1101 / \mathrm{mcs} . a 002279$
Supplementary http://molecularcasestudies.cshlp.org/content/suppl/2018/03/22/mcs.a002279.D Material C1

References This article cites 95 articles, 21 of which can be accessed free at: http://molecularcasestudies.cshlp.org/content/4/2/a002279.full.html\#ref-list-1

License This article is distributed under the terms of the Creative Commons Attribution-NonCommercial License, which permits reuse and redistribution, except for commercial purposes, provided that the original author and source are credited.

Email Alerting Receive free email alerts when new articles cite this article - sign up in the box at the Service top right corner of the article or click here. 